NBER WORKING PAPER SERIES

\title{
LIQUIDITY VS. WEALTH IN HOUSEHOLD DEBT OBLIGATIONS: EVIDENCE FROM HOUSING POLICY IN THE GREAT RECESSION
}

\author{
Peter Ganong \\ Pascal Noel \\ Working Paper 24964 \\ http://www.nber.org/papers/w24964 \\ NATIONAL BUREAU OF ECONOMIC RESEARCH \\ 1050 Massachusetts Avenue \\ Cambridge, MA 02138 \\ August 2018
}

This paper subsumes and extends a paper previously circulated as "The Effect of Debt on Default and Consumption: Evidence from Housing Policy in the Great Recession." We thank Sumit Agarwal, David Berger, John Campbell, Raj Chetty, Gabriel Chodorow-Reich, Joao Cocco, John Coglianese, Marco Di Maggio, Will Dobbie, Jan Eberly, Avi Feller, Xavier Gabaix, John Geanakoplos, Edward Glaeser, Paul Goldsmith-Pinkham, Brett Green, Adam Guren, Sam Hanson, Nathan Hendren, Kyle Herkenhoff, Larry Katz, Rohan Kekre, Ben Keys, Arvind Krishnamurthy, David Laibson, Jens Ludwig, Yueran Ma, Laurie Maggiano, Neale Mahoney, Atif Mian, Kurt Mitman, Bill Murphy, Charles Nathanson, Elizabeth Noel, Christopher Palmer, Jonathan Parker, David Scharfstein, Therese Scharlemann, Antoinette Schoar, Amit Seru, Andrei Shleifer, Jon Spader, Jeremy Stein, Johannes Stroebel, Amir Sufi, Larry Summers, Adi Sunderam, Stijn Van Nieuwerburgh, Joe Vavra, Rob Vishny, Paul Willen, Owen Zidar, and Eric Zwick for helpful comments. We thank Guillermo Carranza Jordan, Chanwool Kim, and Jing Xian Ng for outstanding research assistance. Technical support was provided by the Research Technology Consulting team at Harvard's Institute for Quantitative Social Science. This research uses outcomes calculated based on depersonalized credit data provided by TransUnion, a global information solutions company, through relationships with Harvard University and the University of Chicago Booth School of Business. This research was made possible by a data-use agreement between the authors and the JPMorgan Chase Institute (JPMCI), which has created de-identified data assets that are selectively available to be used for academic research. All statistics from JPMCI data, including medians, reflect cells with at least 10 observations. The opinions expressed are those of the authors alone and do not represent the views of JPMorgan Chase \& Co or the National Bureau of Economic Research. While working on this paper, the authors were compensated for providing research advice on public reports produced by the JPMCI research team. We gratefully acknowledge funding from the Joint Center for Housing Studies, the Washington Center for Equitable Growth, the Hirtle Callaghan Fund, the Charles E. Merrill Faculty Research Fund at the University of Chicago Booth School of Business, and the National Bureau of Economic Research through the Alfred P. Sloan Foundation Grant No. G-2011-6-22 and the National Institute on Aging Grant No. T32-AG000186.

NBER working papers are circulated for discussion and comment purposes. They have not been peer-reviewed or been subject to the review by the NBER Board of Directors that accompanies official NBER publications.

(C) 2018 by Peter Ganong and Pascal Noel. All rights reserved. Short sections of text, not to exceed two paragraphs, may be quoted without explicit permission provided that full credit, including () notice, is given to the source. 
Liquidity vs. Wealth in Household Debt Obligations: Evidence from Housing Policy in the

Great Recession

Peter Ganong and Pascal Noel

NBER Working Paper No. 24964

August 2018

JEL No. D14,G21,R28

\begin{abstract}
We use variation in mortgage modifications to disentangle the impact of reducing long-term obligations with no change in short-term payments ("wealth"), and reducing short-term payments with approximately no change in long-term obligations ("liquidity"). Using regression discontinuity and difference-in-differences research designs with administrative data measuring default and consumption, we find that principal reductions that increase housing wealth without affecting liquidity have no effect, while maturity extensions that increase only liquidity have large effects. Our results suggest that liquidity drives borrower default and consumption decisions, and that distressed debt restructurings can be redesigned with substantial gains to borrowers, lenders, and taxpayers.
\end{abstract}

\author{
Peter Ganong \\ Harris School of Public Policy \\ University of Chicago \\ 1155 E. 60th Street \\ Chicago, IL 60637 \\ and NBER \\ ganong@uchicago.edu \\ Pascal Noel \\ University of Chicago \\ Booth School of Business \\ 5807 South Woodlawn Avenue \\ Chicago, IL 60637 \\ pascal.noel@chicagobooth.edu
}




\section{Introduction}

Record foreclosure rates and reduced aggregate demand during the Great Recession sparked a vigorous policy debate about how to decrease defaults and increase consumption of struggling borrowers. Former Treasury Secretary Timothy Geithner has explained that the government's "biggest debate was whether to try to reduce overall mortgage loans or just monthly payments" (Geithner 2014). A wide range of economists have argued that failing to address debt levels by permanently forgiving mortgage principal was a missed opportunity and one of the biggest policy mistakes of the Great Recession. ${ }^{1}$ Others have argued instead that if borrowers are liquidity constrained, focusing on short-term payment reductions is more cost effective (Eberly and Krishnamurthy 2014).

The normative policy debate hinges on fundamental economic questions about the relative effect of short- vs long-term debt obligations. For default, the underlying question is whether it is primarily driven by a lack of cash to make payments in the short-term or whether it is a response to the total burden of long-term debt obligations, sometimes known as "strategic default." For consumption, the underlying question is whether underwater borrowers have a high marginal propensity to consume (MPC) out of either changes in total housing wealth or changes in immediate cash-flow. ${ }^{2}$ A broad literature evaluates the effects of changes in debt obligations that simultaneously reduce both short-term and long-term payments and consistently shows that debt obligations matter. ${ }^{3}$ Reducing payments leads to decreased defaults and increased consumption. However, to fully understand the effect of debt on borrower decisions and to inform the debate about liquidity- versus wealth-focused interventions, it is essential to separately estimate the effect of short-term and long-term debt reductions.

We fill this void by exploiting two natural experiments to separately identify the impact of reducing long-term obligations without changing short-term payments ("wealth"), and reducing short-term payments without changing long-term obligations ("liquidity"). We find that mortgage principal reduction that increases housing wealth without affecting liquidity has no significant impact on default or consumption for underwater borrowers. In contrast, we show that maturity extension, which immediately reduces payments but leaves long-term obligations approximately unchanged, does significantly reduce default rates. ${ }^{4}$ Taken together, these results suggest that liquidity is the key driver of borrower default and consumption decisions. Furthermore, we show that this lesson can be used to inform the efficient design of distressed debt restructurings, with the potential for substantial gains to

\footnotetext{
${ }^{1}$ See Goldfarb (2012) for a review of the academic support for principal reductions. Geanakoplos and Koniak (2009) argued that a plan to reduce payments and leave principal unchanged "wastes taxpayer money and won't fix the problem." See also Feldstein (2009), Romer (2011), and Mian and Sufi (2014b).

${ }^{2}$ An "underwater" or negative equity borrower owes more on their home than its current market value.

${ }^{3}$ See Agarwal et al. (2017a), Agarwal et al. (2017b), Abel and Fuster (2018), DiMaggio et al. (2017), Ehrlich and Perry (2015), Fuster and Willen (2017), and Tracy and Wright (2016).

${ }^{4}$ Although our research designs are underpowered for estimating the causal effect of payment reductions on consumption, we provide suggestive evidence that payment reductions also increase spending.
} 
borrowers, lenders, and taxpayers.

Our first natural experiment allows us to isolate the effect of wealth by comparing underwater borrowers who receive two types of modifications in the federal government's Home Affordable Modification Program (HAMP). Both modification types result in identical payment reductions for the first five years. However, one group also receives an average of $\$ 67,000$ in mortgage principal forgiveness, which translates into long-term payment relief. Because borrowers remain slightly underwater even after substantial principal forgiveness, their short-term access to liquidity is unchanged. By exploiting quasi-experimental assignment of borrowers to each of these modification types, we isolate the effects of long-term debt levels holding fixed short-term liquidity.

Our second natural experiment exploits an eligibility cutoff rule for HAMP that generates the opposite treatment: an increase in liquidity with approximately no change in wealth. Borrowers above the cutoff receive small payment reductions from HAMP while borrowers below the cutoff are ineligible for the government program but receive larger payment reductions through alternative private sector modifications. Government program rules prohibit the private sector from offering these alternative modifications to eligible borrowers above the cutoff under the (erroneous) assumption that the government-subsidized modifications would always be more effective. The private sector finances these deeper payment reductions by first extending mortgage maturities prior to additional modification steps, such that larger immediate payment reductions are offset by continued payments in the long term. This restructuring leaves the net present value of total mortgage payments owed approximately unchanged. By comparing borrowers on either side of this cutoff we isolate the effect of immediate liquidity provision holding fixed long-term wealth.

To study these natural experiments we build two new datasets with information on borrower outcomes and program participation. Our first dataset matches administrative data on HAMP participants to monthly consumer credit bureau records. We exploit detailed account-level information to construct a novel measure of consumer spending based on monthly credit card expenditures. We also follow DiMaggio et al. (2017) by using new auto loan originations as a proxy for durable consumption. Our second dataset uses deidentified mortgage and credit card data from the JPMorgan Chase Institute (JPMCI). It includes monthly information on all borrowers whose mortgages are serviced by Chase and who receive either a government-subsidized modification through HAMP or an alternative private modification. Our samples from both datasets are similar on observable borrower characteristics.

Our empirical analysis proceeds in three steps. First, we estimate the causal impact of principal reduction on default by exploiting a cutoff rule in borrower assignment to the two HAMP modification types. Mortgage servicers evaluated underwater applicants for both modification types by calculating the expected gain to investors under either option using a standard government-supplied formula. There is a sharp 41 percentage point jump in the 
probability that a borrower receives principal reduction when the calculation shows that principal reduction is marginally more beneficial to investors. We exploit this jump with a regression discontinuity estimator comparing borrowers on either side of this cutoff.

We find that principal reduction has no effect on default. Despite a $\$ 30,000$ increase in principal forgiveness in the treatment group at the cutoff (translating to an 11 percentage point reduction in a borrower's loan-to-value ratio), default rates are unchanged. We calculate that even at the upper bound of our confidence interval, the government spent $\$ 556,000$ per avoided foreclosure. This cost is over an order of magnitude greater than estimates of the social cost of foreclosures (U.S. Department of Housing and Urban Development 2010).

In the second step of our empirical analysis we examine the causal impact of principal reduction on consumption. Our preferred empirical strategy for analyzing consumption is a panel difference-in-differences estimator which is more precise than our regression discontinuity strategy. ${ }^{5}$ We compare HAMP borrowers who receive principal reductions to other HAMP borrowers who receive only payment reductions. We find that an average of $\$ 67,000$ in principal reduction has no significant impact on underwater borrowers' credit card or auto expenditure. Translating our results into an annual MPC for total consumption, our point estimate is that borrowers increased consumption by three-tenths of one cent per dollar of principal reduction, with an upper bound of eight-tenths of one cent.

In the third step of our empirical analysis we estimate the causal impact of immediate payment reductions on default. This analysis exploits HAMP's eligibility cutoff using a regression discontinuity design. There is an 18 percentage point jump in the amount of payment reduction received by borrowers with private modifications just below the cutoff. Although there is a large change in immediate liquidity at the cutoff, because these deeper payment reductions are largely financed by extending mortgage maturities there is no significant change in the net present value of total long-term payments owed.

In contrast to our results on the ineffectiveness of principal reduction, we find that immediate payment reduction significantly reduces default rates. Default rates fall sharply by six percentage points at the cutoff from a control mean of 32 percentage points, implying that a one percent payment reduction reduces default rates by about one percent. While our data and available research designs are unsuited for credibly estimating the causal effect of immediate payment reduction on consumption, we provide suggestive evidence from the timeseries pattern of spending around modification that spending also rises when monthly payments fall.

Combining the three steps of our empirical analysis, the central contribution of this paper is to disentangle the effects of liquidity and wealth on mortgagor outcomes. Disentangling these effects allows us to draw two types of lessons. First, from a positive perspective, we shed light on the mechanisms underlying the previously-documented relationships between

\footnotetext{
${ }^{5}$ We also report estimates from the regression discontinuity design and show that this strategy is statistically and economically uninformative for analyzing consumption outcomes.
} 
housing wealth, housing debt, default, and consumption. Second, from a normative perspective, we use these results to inform the debate about the efficient structure of re-negotiations during a debt crisis.

For default, we show that the strong cross-sectional relationship between leverage and default is not causal for underwater borrowers. Instead of borrowers defaulting for strategic reasons, we find that borrower default decisions are based primarily on immediate liquidity. ${ }^{6}$ The cross-sectional evidence may have been misleading because borrowers with less equity purchased homes near the height of the credit boom and were less creditworthy on other dimensions (Palmer 2015), or because the large price reductions that left many borrowers underwater were also correlated with other omitted economic shocks that themselves could be responsible for higher default rates (Adelino et al. 2016).

From a specific policy perspective, our default results suggest a significant inefficiency at the HAMP eligibility cutoff. The government spent substantial resources subsidizing HAMP modifications above the cutoff with small payment reductions and high default rates, whereas borrowers below the cutoff received private modifications requiring no government assistance, which had large payment reductions and low default rates. In fact, there is likely a Pareto improvement for borrowers, lenders, and taxpayers from shifting the cutoff such that fewer borrowers receive HAMP and more borrowers receive private modifications. We find that 40 percent of HAMP borrowers are in the region where a private alternative, such as the one we study, would have provided deeper payment reductions and led to reduced default rates. Government rules prohibiting servicers from offering these private bilateral alternatives based on the assumption that proprietary modifications could not be as effective as those subsidized by the government may have crowded out more effective modifications for these borrowers. Our finding that payment reductions can be structured so as to reduce default rates while leaving all parties better off contrasts sharply with our finding for principal reduction, which was ineffective for borrowers even while being costly to both lenders and taxpayers.

From a broader policy perspective, this lesson can be used to characterize the defaultminimizing modification structure for all borrowers. Since immediate liquidity provision reduces default rates but long-term wealth does not, the efficient modification structure maximizes short-term liquidity provision, in the spirit of Eberly and Krishnamurthy (2014). We trace out the default-minimizing modification frontier and find the potential for substantial gains to borrowers, lenders, and taxpayers.

We consider two ways to quantify the potential gains of more efficient modifications relative to the type of restructurings previously pursued. First, we calculate that the median amount of payment reduction in HAMP could have been provided at a $\$ 63,000$ lower cost per modification to lenders and taxpayers (a savings of 26 percent of the unpaid balance),

\footnotetext{
${ }^{6}$ Our results are consistent with the default rate mechanically increasing once borrowers move from positive to negative equity, since this has a large negative liquidity effect. Above water borrowers can avoid default by selling their home or borrowing against their home (Gupta and Hansman 2018).
} 
translating to a total potential unnecessary cost of $\$ 108$ billion aggregating over all HAMP modifications. Alternatively, if modifications maximized the amount of payment reduction while holding costs fixed, it would have been possible to cut default rates by one-third, avoiding 240,000 defaults at no additional cost to lenders or taxpayers.

For consumption, we show that the tight link between housing wealth and consumption breaks down when borrowers are underwater. Our estimated MPC out of housing wealth for underwater borrowers is an order of magnitude smaller than the MPC for average homeowners examined in prior studies. ${ }^{7}$ Furthermore, prior research has found high-leverage borrowers appear to be even more responsive. Mian et al. (2013) find that households living in zip codes with average loan-to-value (LTV) ratios above 90 have MPCs that are twice that of the median household, translating into an MPC of 18 cents. This result has been used by policy advocates arguing in favor of principal reduction for underwater borrowers (Goldfarb 2012). However, our evidence suggests that borrowers who are far underwater have much lower MPCs out of housing wealth, rendering principal reductions for these borrowers ineffective.

We argue that the inability of underwater borrowers to monetize the wealth gains from principal reduction can explain why they are far less sensitive to housing wealth changes than borrowers in other economic conditions. Typically, housing wealth gains expand borrowers' credit access (Mian and Sufi 2014a). But if homeowners face a collateral constraint, principal reduction that still leaves borrowers underwater or nearly underwater will not immediately relax this constraint, which may explain why principal reduction is ineffective. We develop a partial-equilibrium life cycle model to formally analyze whether a delay in being able to access housing wealth can explain why consumption is unaffected by principal reduction. The model shows that collateral constraints drive a wedge between the MPC out of cash and the MPC out of housing wealth for underwater borrowers. Thus, policies to increase housing wealth are unable to stimulate demand when borrowers are so far underwater that home equity gains fail to relax binding collateral constraints, which was precisely the situation when such policies were implemented.

This paper contributes to several additional strands of the literature. Scharlemann and Shore (2016) analyze principal reduction in HAMP using a regression kink design and also find that principal reduction is a costly way to reduce defaults. Relative to Scharlemann and Shore (2016), our contributions are the introduction of a regression discontinuity design that requires weaker parametric assumptions, an examination of the impact of principal reduction on consumption and payment reduction on default, and the development of a model that clarifies the mechanisms causing principal reductions to be ineffective. ${ }^{8}$ Agarwal

\footnotetext{
${ }^{7}$ See Aladangady (2017), Attanasio et al. (2009), Berger et al. (2018), Campbell and Cocco (2007), Carroll et al. (2011), Case et al. (2013), and Guren et al. (2018b).

${ }^{8}$ Outside of mortgages, Dobbie and Song (2016) analyze future payment reductions for credit card borrowers. In contrast to our findings, they find that reducing future payments by 8 percent of the total debt owed leads to a reduction in short-term default of 1.6 percentage points. When scaled to to an equivalent treatment size, this is larger than our point estimate but within our confidence interval. One possible expla-
} 
et al. (2017a) study the overall effect of HAMP modifications, which combine both shortterm and long-term payment reductions. We complement their findings by separating the effect of long-term from short-term payment reductions, providing evidence that shortterm payment reductions are largely responsible for the program's effects. This allows us to identify the underlying mechanisms driving borrower responses to debt reductions and therefore to analyze the optimal structure of debt renegotiations. These empirical lessons about ex-post renegotiation also help inform a growing theoretical literature about optimal ex-ante mortgage design. ${ }^{9}$

Our model also contributes to a new literature finding little direct linkage between debt levels and consumption when debt is modeled as a long-term contract (Kaplan et al. 2017, Justiniano et al. 2015). This contrasts with debt overhang models in which forced deleveraging of short-term debt leads to depressed consumption during a credit crunch (Eggertsson and Krugman 2012, Guerrieri and Lorenzoni 2017). In our model, as in practice, nothing forces borrowers to immediately delever when they are far underwater, removing a mechanical link between debt levels and consumption present in some of the prior literature and reducing the expected effectiveness of principal reduction.

The remainder of the paper is organized as follows. Section 2 describes the data. Sections 3 and 4 analyze the effect of principal reduction on default and consumption, respectively. Section 5 analyzes the effect of payment reduction on default. Section 6 discusses the implications of our default results. Section 7 discusses the implications of our consumption results. The last section concludes.

\section{Data}

We use two datasets. Our first dataset matches administrative HAMP participation data to consumer credit bureau records. This dataset covers a broad sample population and allows us to carefully analyze the mechanisms assigning borrowers to each modification type in HAMP, which we exploit to estimate the impact of principal reduction. Our second dataset comes from a bank that is also a servicer that offers both government-subsidized HAMP modifications as well as private modifications. This allows us to analyze variation in immediate payment reduction between public and private modifications and to examine administrative spending data.

\subsection{Matched HAMP Credit Bureau File}

The U.S. Treasury releases a public data file on the universe of HAMP applicants. This loan-level dataset includes information on borrower characteristics and mortgage terms before and after modification. Crucially, it also includes the NPV calculations run by

nation is that borrowers behave more strategically with respect to credit card debt because the consequences of default are less severe than defaulting on a mortgage, which often results in foreclosure.

${ }^{9}$ See Piskorski and Tchistyi (2010), Eberly and Krishnamurthy (2014), Guren et al. (2018a), Campbell et al. (2018), and Greenwald et al. (2018). 
servicers when evaluating borrowers for each modification type.

In order to observe a wide range of borrower outcomes, we use depersonalized consumer credit bureau records from TransUnion. HAMP program rules require servicers to report borrower participation to credit bureaus. We use the universe of records for borrowers flagged as having received HAMP. We have monthly account-level information between January 2010 and December 2014 for each borrower.

We develop proxies for both durable and nondurable consumption based on the credit bureau records. For durable consumption, we follow DiMaggio et al. (2017) by using changes in auto loan balances as a measure of car purchases. DiMaggio et al. (2017) document that leveraged car purchases account for 80 percent of total car sales. While prior work relied on observing jumps in total auto loan balances to infer new loans, our product account-level data allows us to observe new loans directly.

The detailed nature of our credit bureau data also allow us to construct a new measure of consumption based on credit card expenditures. In particular, we calculate monthly expenditures using end of month balances and payments made in a given month. ${ }^{10}$ We are able to construct this measure for 83 percent of all credit and charge card accounts (not all servicers report monthly payments). We find average credit card spending of $\$ 425$ per month in our sample, which is 80 percent of the average credit card spending per adult in 2012 (Federal Reserve 2014), commensurate with the 83 percent of cards for which we observe expenditures.

We match borrowers in the HAMP dataset to their credit bureau records using loan and borrower attributes present in both files. The attributes we use are metro area, modification month, origination year, loan balance, and monthly payment before and after modification. When two borrowers are listed on a mortgage, we measure consumption using the credit bureau records of both borrowers. We are able to match half of the records in our sample window, resulting in a panel dataset of about 106,000 underwater households eligible for both HAMP modification types. ${ }^{11}$

The imperfect match rate does not bias our sample along any observed borrower characteristics. Online Appendix Table 1 reports summary statistics for our sample before and after the credit bureau match. This table shows that borrower characteristics are similar in the matched sample. The final column shows that the difference in means for any characteristic is less than one-fifth of a standard deviation. For our regression discontinuity

\footnotetext{
${ }^{10}$ Let $b_{t}$ denote the balance at the end of month $t$, and $p_{t}$ be the payment made in month $t$. We calculate expenditure in month $t$ as $e_{t}=b_{t}-b_{t-1}+p_{t}$. Because interest rates and fees are not reported, we do not distinguish between new purchases, interest charges, and fees in this dataset. In the bank dataset described in Section 2.2 we can isolate purchases and confirm that our results are unchanged.

${ }^{11}$ Our match rate is less than 100 percent due to rounding and changing reporting requirements. The main data limitation is that pre-modification principal balance and monthly payment fields are rounded in the Treasury HAMP file, which introduces a discrepancy between the same loans in both files. Another limitation is that the Treasury file required new reporting processes for participating servicers, and the reporting requirements changed several times as the program developed. As a result, Treasury explains that there are occasional inaccuracies in the underlying data (U.S. Department of Treasury 2014).
} 
design to identify the causal impact of principal reduction on default in the presence of incomplete matching, we need the match rate to be smooth at the cutoff. We show that this is the case in online Appendix Figure 1. In Section 4.2 we show that our consumption result is unchanged (though slightly less precise) when we estimate it using the subsample of borrowers in the bank dataset, which does not rely on matching and is described in the following section.

\subsection{JPMCI Bank Dataset}

Our second dataset includes de-identified account-level monthly information on all mortgages serviced by Chase bank and spending by mortgagors who also had a Chase credit card. The dataset covers 2009 to 2016. We focus on two subsamples of borrowers. The sample we use as a robustness check to study the effect of principal reduction on consumption includes all HAMP borrowers with both a mortgage and a credit card with Chase. We observe credit card spending for 22,924 borrowers one year before and after modification.

The sample we use to study the effect of payment reduction includes all borrowers who receive either a government-subsidized HAMP or private modification. This includes 60,000 mortgages owned or securitized by Fannie Mae and Freddie Mac (the GSEs) and 86,000 mortgages which are owned or have been securitized by Chase. We limit the sample to modifications performed in the fourth quarter of 2011 or later, when the particular versions of the private programs we study were sufficiently established. ${ }^{12}$ We analyze the impacts on GSE-backed and non-GSE-backed mortgages separately in Section 5.

\section{Effect of Principal Reduction on Default}

In this section we analyze the effect of principal reduction on borrower default. We compare borrowers who received two different types of government-subsidized modifications, with both types receiving identical short-term payment reductions but one type receiving additional principal reduction. Using a regression discontinuity empirical strategy we find that substantial principal reductions have no effect. We can rule out prior cross-sectional estimates that were used to justify the program.

\subsection{Variation in Payment and Principal Reduction in the Home Afford- able Modification Program}

The government instituted the HAMP program in 2009 as a response to the foreclosure crisis. It provided government subsidies to help facilitate mortgage modifications for borrowers struggling to make their payments. In total, 1.7 million borrowers received modifications through the program.

The government designed HAMP's eligibility criteria to target the borrowers it perceived

\footnotetext{
${ }^{12}$ Both Chase and the GSEs had a variety of other private modification programs with different designs that preceded HAMP.
} 
as most likely to benefit from modifications. Borrowers must have current payments greater than 31 percent of their income, be delinquent or in imminent default at the time of their application, attest that they are facing a financial hardship that makes it difficult to continue making mortgage payments, and report that they do not have enough liquid assets to maintain their current debt payments and living expenses. In almost all cases, borrowers must be owner-occupants and have loan balances of less than $\$ 730,000 .{ }^{13}$

The primary goal of HAMP modifications is to provide borrowers with more affordable mortgages. All borrowers who receive modifications have their payment reduced to reach a 31 percent Payment-to-Income (PTI) ratio for at least five years. This rule results in substantial modifications for many borrowers. The mean payment reduction is $\$ 680$ per month, or 38 percent of the borrower's prior monthly payment.

Our research design relies on contrasting borrowers assigned to two distinct modification types. Both modification types result in the same payment reduction for the first five years, but each type achieves this payment reduction in a different way.

The first modification type provides what we call a "payment reduction" modification. Figure 1a shows the average annual payments for borrowers in this modification type relative to their payments under the status quo. This modification implements up to three steps to achieve the 31 percent PTI target. First, the interest rate is reduced down to a floor of two percent for a period of five years, after which it gradually increases to the market rate. Second, if the target is not reached after the interest rate reduction, the mortgage maturity is extended up to 40 years. Third, if the target still is not reached, a portion of the unpaid balance is converted into a non interest-bearing balloon payment due at the end of the mortgage term.

The second modification type is what we call a "payment and principal reduction" modification (also known as the HAMP Principal Reduction Alternative). The first step in this modification is to forgive a borrower's unpaid principal balance until the new monthly payment achieves the 31 percent PTI target or their LTV ratio hits 115 percent, whichever comes first. If the borrower's monthly payment is still above the target, then the interest rate reduction, maturity extension, and principal forbearance steps described above are followed as needed. 241,000 borrowers received these modifications.

The government introduced these principal reduction modifications in 2010 in response to growing concern that debt levels, rather than just debt payments, were responsible for high default rates and depressed consumption. The government devoted substantial resources towards supporting principal reduction modifications. On average, the government paid an additional $\$ 21,000$ per modification to support modifications with principal reduction (Scharlemann and Shore 2016).

\footnotetext{
${ }^{13}$ These criteria rule out borrowers who might be particularly likely to strategically default. However, such borrowers are responsible for a small share of defaults. Eighty-seven percent of defaults in 2009 were for owner-occupied mortgages (Agarwal et al. (2017a) Table 1) and combining the SCF and the PSID we calculate that 95 percent of defaults were for loans below this balance threshold.
} 
By comparing borrowers who receive these two types of modifications, we can estimate the effect of long-term debt obligations holding short-term payments constant. The two types of modifications have identical effects on payments in the short term, but dramatically different effects on long-term payments and homeowner equity. Figure 1a shows that payment reductions are identical for the first five years, after which payments rise more sharply for borrowers with payment reduction modifications. Figure 1b summarizes the financial impacts of these modifications for borrowers in our sample. Borrowers with principal reduction modifications receive an average of $\$ 67,000$ more principal reduction. ${ }^{14}$

The monetary value of the principal reduction depends on borrower behavior. To a borrower who prepays her mortgage the next day, principal reduction is worth $\$ 67,000$, but it is worth nothing to a borrower who immediately defaults and never repays. We calculate the value to borrowers using two methods. First, we calculate that the incremental reduction in the Net Present Value (NPV) of payments owed under the mortgage contract if the borrower repays on schedule is $\$ 34,000$. This calculation assumes borrowers discount future cash flows at the average market interest rate, consistent with the empirical findings in Busse et al. (2013) for auto loans. ${ }^{15}$

Second, we calculate the NPV of expected payments using observed prepayment and default behavior of HAMP borrowers. For default, we use a lifetime liquidation rate of $32 \%$ based on public HAMP performance data and provide details on our valuation method in online Appendix C.1. Prepayment raises the NPV and default lowers it. The default effect dominates and we calculate a change in NPV of $\$ 28,000$.

Program administrators took steps to ensure that borrowers understood the new mortgage terms. The cover letter for the modification agreement prominently listed the new interest rate, mortgage term, and amount of principal reduction. Additionally, the modification agreement included a summary showing the new monthly payment each year, as shown in online Appendix Figure 2. Borrowers appear eager to take up modifications. Conditional on being offered a modification, 97 percent of borrowers accepted the offer.

\subsection{Identification: Discontinuity in Principal Reduction at Treasury Model Cutoff}

During the Great Recession, there were concerns that a large share of defaults were "strategic" in nature, committed by borrowers who only had negative equity rather than by borrowers with affordability problems (Zingales 2010, Winkler 2010, Experian and Wyman

\footnotetext{
${ }^{14}$ Some borrowers in the payment reduction modification type received small amounts of principal reduction. This is because some servicers wanted to provide principal forgiveness outside of the Treasury incentive program, which only paid incentives for forgiveness above 105 percent LTV and required the forgiveness to vest over three years.

${ }^{15}$ This is also consistent with a "market-based" conception of wealth where valuation does not differ across individuals. However, for an individual conception of wealth, the gains are still substantial even for a more impatient borrower. For example, if instead we assume the borrower's discount rate is twice the mortgage interest rate, principal forgiveness reduces the NPV of payments owed under the contract by $\$ 18,000$.
} 
2009). To assess the extent of strategic default, the ideal experiment would randomly assign borrowers to different levels of negative equity holding fixed immediate monthly payments. As in HAMP, in this ideal experiment the treatment group would remain slightly underwater even after principal reduction. This is because bringing borrowers above water may enable borrowers to avoid default by selling the home or borrowing against the home (Gupta and Hansman 2018), and hence would not be informative about the prevalence of strategic default.

In lieu of this ideal experiment, we have a setting in HAMP where borrower assignment to different levels of negative equity is determined in part by a cutoff rule, and in part by servicer and lender type. This assignment generates quasi-experimental variation in which modifications borrowers receive, which we will exploit in our empirical strategies. We discuss the cutoff rule--which we use in a regression discontinuity to estimate the impact of principal reduction on default-in this section. We use variation in servicer and lender type to estimate consumption impacts, and so we defer an explanation of that variation to Section 4.

Our quasi-experimental variation covers the period with the most severe delinquency rates in the recent crisis. Our sample of borrowers have their first delinquencies in the fourth quarter of 2009, just before the peak of the delinquency crisis, which did not begin abating until 2013. Online Appendix Figure 3 plots the delinquency rate for all U.S. borrowers over time.

Principal reduction is determined in part by a calculation examining which modification type is expected to be most beneficial for the lender. Using a model developed by the U.S. Treasury Department, servicers calculate the expected NPV of cash flows for lenders under the status quo and under each of the two modification options. The NPV model takes into consideration government-provided incentives as well as the expected impact that modifications will have on default and prepayment.

Our empirical strategy exploits a large jump in the share of borrowers receiving modifications with principal reductions when the NPV model shows it will be more beneficial to lenders than the alternative. This jump is shown in Figure 2a. The purpose of the Treasury NPV model is to reduce contracting frictions between lenders and servicers. Servicers are bound by their fiduciary duty to the lenders to maximize repayment, and as a result are more likely to offer the modifications shown to be most beneficial to lenders.

We identify the effect of principal reduction on default using the cutoff in the expected benefit to lenders with a regression discontinuity research design. Let the receipt of principal reduction treatment be denoted by the dummy variable $T \in\{0,1\}$, where 0 represents receiving a payment reduction modification, and let $X$ capture the characteristics of the borrower. The Treasury NPV model calculates the expected net present value to lenders $\operatorname{ENPV}(T, X)$ under either scenario. Our running variable $V$ is the normalized predicted 
gain to lenders of providing principal reduction to borrowers, i.e.

$$
V(X)=\frac{E N P V(1, X)-E N P V(0, X)}{E N P V(0, X)} .
$$

A realization $v$ reflects the expected percent gain to the lender from principal reduction relative to a standard modification. The cutoff that affects assignment to treatment or control is at $v=0$. These are borrowers for whom the increased government incentive payments and the reduction in default expected by the Treasury NPV model generate gains to lenders that offset lenders' cash-flow loss from forgiving principal. We normalize the predicted gain to avoid a high concentration of low-balance mortgages near the cutoff, though our key finding that principal reduction does not affect default is insensitive to this normalization.

The treatment effect of receiving principal reduction is determined by the jump in default divided by the jump in the share receiving principal reduction at the cutoff. Let $Y$ be the outcome variable of interest (such as default). The fuzzy regression discontinuity (RD) estimand is given by

$$
\tau=\frac{\lim _{v \downarrow 0} E[Y \mid V=v]-\lim _{v \uparrow 0} E[Y \mid V=v]}{\lim _{v \downarrow 0} E[T \mid V=v]-\lim _{v \uparrow 0} E[T \mid V=v]} .
$$

We follow the standard advice for Regression Discontinuity Designs from Lee and Lemieux (2010) and Imbens and Kalyanaraman (2012) to estimate $\hat{\tau}$ using a local linear regression. Our analysis dataset is the matched HAMP credit bureau dataset, which includes the predicted gain to investors of providing principal reduction $v$.

In Table 1a we compare summary statistics for borrowers in our sample near the assignment cutoff to the characteristics of delinquent borrowers in the Panel Study of Income Dynamics between 2009 and 2011. Borrowers in our sample are broadly representative of delinquent underwater borrowers during the recent crisis. We provide more detail on this comparison in online Appendix Section B.1.1.

Predicted default rates based on pre-determined covariates trend smoothly through the cutoff, as shown in online Appendix Figure 4. Some servicers ran only one NPV calculation and reported this single number as the NPV calculation for both "payment reduction" and "payment \& principal reduction" modifications, meaning that they reported $\operatorname{ENPV}(1, X)=$ ENPV $(0, X)$. Following the advice of U.S. Treasury staff, we assume observations exactly at zero reflect misreporting and drop them from the analysis sample. Online Appendix Figure 5 shows that density in the analysis sample is smooth around the cutoff. We provide additional detail on both covariate balance and smoothness in online Appendix B.1.2.

\subsection{Results: Effect of Principal Reduction on Default}

Figure 2a shows that there is a discontinuous jump of 41 percentage points in the share of borrowers receiving principal reduction at the cutoff. Measured in terms of dollars of 
principal reduction, the treatment size at the cutoff is $\$ 30,000$. This reduces borrower LTV by 11 percentage points, and amounts to a $\$ 17,000$ reduction in the NPV of borrower payments owed over the full mortgage term. Importantly, there is no jump in monthly payment reduction at the cutoff, highlighting that the "treatment" we are analyzing is a reduction in mortgage principal that leaves short-term payments unchanged. The relationship of the four aforementioned variables with respect to the running variable is shown in online Appendix Figure 6 .

We find that principal reduction has no impact on default. Figure $2 \mathrm{~b}$ shows the reduced form of the fuzzy regression discontinuity specification, plotting the default rate against the running variable. We define our main measure of default as being 90 days delinquent at any point between modification date and March 2015, when our dataset ends, which is an average of three years. This is the measure of default used to disqualify a borrower from the HAMP program and is the common measure used in the prior literature discussed in section 3.4. There is no jump in default rates at the cutoff. Our point estimate is that $\$ 30,000$ of principal reduction changes default probabilities by less than one percentage point, and we can rule out a reduction of more than five percentage points. Online Appendix Figure 7 shows that our estimates are close to zero for a wide range of bandwidth choices, and these results are discussed in more detail in online Appendix B.1.2.

Our evidence suggests that principal reduction is also ineffective at reducing foreclosures. Online Appendix Figure 8 shows that there is no jump in the foreclosure initiation rate at the cutoff. ${ }^{16}$ It is not surprising that the same pattern would be seen in foreclosures as in defaults. Borrowers who have defaulted and are unable to self-cure are generally unable to sell their home to avoid foreclosure while they are underwater.

Our results imply a large government cost per avoided foreclosure. The upper bound of our 95 percent confidence interval suggests foreclosure initiations were reduced at most by 3.6 percentage points. Herkenhoff and Ohanian (2015) document that approximately half of borrowers with a foreclosure initiation end up with a completed foreclosure, while the other half self-cure. This suggests that principal reduction reduced foreclosure completions by at most 1.8 percentage points during the window we study. ${ }^{17}$ The government spent about $\$ 10,000$ per modification to support the additional principal reduction of the size we analyze in our treatment group. This translates into a government cost of at least $\$ 556,000$ per avoided foreclosure, more than an order of magnitude larger than common estimates of the social costs of foreclosure (Department of Housing and Urban Development 2010).

It is possible that foreclosures would have been mechanically avoided by bringing bor-

\footnotetext{
${ }^{16}$ Due to the lengthy delay between foreclosure initiations and foreclosure completions, foreclosure completions are rarely observed in our sample period.

${ }^{17}$ Although we find little impact on foreclosures within our three-year analysis window, it is possible that once these borrowers regain positive equity several years in the future, foreclosures for the principal reduction group will be lower than for those who did not receive it. Unfortunately this is not something we can analyze with the data in this paper. Furthermore, to the extent that the policy goal was short-term housing market stabilization, the benefit of future foreclosure reduction is unclear.
} 
rowers all the way into positive equity, but this also would have been an expensive strategy after prices had fallen substantially. The average underwater borrower evaluated for principal reduction had about $\$ 100,000$ in negative equity. Even if foreclosure initiations were completely eliminated by forgiving 100 percent of this negative equity (since defaulting borrowers could sell their home and avoid a foreclosure), this would require $\$ 2.5$ million in writedowns to avoid a subsequent foreclosure initiation and $\$ 5$ million to avoid a foreclosure completion.

\subsection{Comparison to Prior Evidence on Default}

Our results are inconsistent with prior evidence based on cross-sectional relationships. For example, Haughwout et al. (2016) use data on modifications performed prior to HAMP and find using cross-sectional variation that borrowers who received principal reductions equivalent to ours saw an 18 percentage point reduction in default. Furthermore, there is a strong cross-sectional relationship between the amount of negative equity and default rates across all borrowers (Gerardi et al. 2015).

Indeed, the U.S. Treasury Department developed a model based on this historical data that predicts a substantial reduction in default from principal reduction, which is inconsistent with our findings. The Treasury generated this estimate as part of its model to predict the benefits of modifications to lenders (Holden et al. 2012). We implement the Treasury redefault model (U.S. Department of the Treasury 2015) in the public HAMP data and calculate the predicted impact of principal reduction at the cutoff. The Treasury model expects a sharp reduction in default of 6.6 percentage points at the NPV cutoff, which we can rule out using the lower bound of our 95 percent confidence interval. This implies that many lenders were actually worse off from having offered principal reduction, since the expected reduction in defaults necessary to offset the reduced cash flow from borrowers did not materialize.

Why is our causal estimate so much smaller than what is predicted by the cross-sectional relationship between borrower equity and default and models calibrated to this relationship? One possibility is that the cross-sectional evidence was misleading because borrowers with less equity were also borrowers who purchased homes near the height of the credit boom and who therefore might have been less credit-worthy on other dimensions. Palmer (2015) shows that changes in borrower and loan characteristics can explain 40 percent of the difference in default rates between the 2003-2004 and the 2006-2007 cohorts. Another possibility is that the large price reductions that left many borrowers underwater were also correlated with other omitted economic shocks that themselves could be responsible for higher default rates (Adelino et al. 2016).

In contrast to these cross-sectional estimates, Scharlemann and Shore (2016) analyze principal reduction in HAMP using a regression kink design, and also find that principal 
reduction is a costly way to reduce defaults. ${ }^{18}$ Our empirical results reinforce the conclusions of Scharlemann and Shore (2016) using an alternative estimation strategy that requires weaker parametric assumptions. In Scharlemann and Shore (2016)'s preferred specification, they use a regression kink design and assume that the relationship between the running variable and the outcome variable is globally linear. In contrast, our regression discontinuity identification strategy assumes that unobservable borrower traits are smooth in the local region around the cutoff.

\section{Effect of Principal Reduction on Consumption}

In this section we explore the effect of principal reductions on consumption. We find that the marginal propensity to consume out of housing wealth for underwater borrowers is an order of magnitude smaller than the marginal propensity to consume for average homeowners examined in prior studies.

\subsection{Identification: Panel Difference-in-Difference Empirical Strategy}

Our use of consumption data motivates a change in research design to a panel differencein-differences strategy for two reasons. First, our regression discontinuity strategy is underpowered for studying changes in consumption. Economically meaningful consumption changes can not be ruled out in the regression discontinuity sample given lack of precision. As we discuss in more detail in Section 4.3, even a small change in consumption on the order of five percent of the amount of principal forgiven would be meaningful relative to average marginal propensities to consume out of housing wealth changes studied in other contexts, whereas the predicted impacts on default from the prior literature were much larger. The second reason is that the panel nature of the spending measures from our credit bureau and banking data allow us to exploit an alternative strategy that offers more precision. Lagged spending measures allow us to adjust for underlying differences between borrowers receiving different modification types within a wider bandwidth than with the regression discontinuity. These factors favor a panel difference-in-differences design, though we also report results from the regression discontinuity strategy. ${ }^{19}$

Our panel difference-in-differences design uses as a control group the set of underwater borrowers who were eligible for principal reductions, but who instead received only payment reduction modifications. This design relies on the fact that borrowers who receive payment reduction modifications experience the same short-term payment reductions as borrowers

\footnotetext{
${ }^{18}$ In their preferred specification, where they use the global relationship between default and principal reduction, they find that principal reduction of the size we estimate (reducing the LTV by 11 points) reduces default by 1.9 percentage points, a result that is within our confidence interval. When using data close to the kink, they find that principal reduction has no statistically or economically significant effect on default.

${ }^{19} \mathrm{We}$ also have lagged measures of default from the credit bureau data. However, a difference-in-differences design is not valid for default because pre-treatment differences in the levels of default are mechanically removed at modification date, at which point all loans become current. This means that the change in default for the control group is not a valid counterfactual for the change in the treatment group.
} 
who receive principal reduction, but receive substantially less generous long-term payment relief. Summary statistics for both groups are shown in online Appendix Table $2 .{ }^{20}$ The size of short-term payment reductions are nearly identical across groups, but borrowers who receive payment and principal reduction modifications receive on average $\$ 67,000$ more principal reduction, reducing the NPV of the payments owed under their mortgage contract by an additional $\$ 34,000$. In accordance with the HAMP rules described in the previous section, borrowers who received principal forgiveness remained underwater (usually at 115 percent LTV). Thus, the treatment is the effect of long-term debt forgiveness holding shortterm payments and access to liquidity fixed.

Our identification comes from cross-servicer and cross-lender variation in the propensity to provide principal reductions given observed borrower characteristics. Borrowers are not assigned to principal reduction modifications according to the NPV calculation alone because different lenders have different views about principal reduction and servicers are not always confident they have the contractual right to forgive principal or the capacity to manage the process. ${ }^{21}$ Conditional on lender and servicer, all borrowers are treated alike. Servicers must submit a written policy to the Treasury department detailing when they will offer principal reduction modifications and attesting that they will treat all observably similar borrowers alike (U.S. Department of Treasury 2014). Intuitively, comparing borrowers across modification types relies on servicer-lenders that were more likely to offer principal reduction not having borrowers whose consumption was trending differentially relative to borrowers whose servicer-lenders were less likely to offer principal reduction.

The key identifying assumption for the panel difference-in-differences design is that consumption trends would be the same in both groups in the absence of treatment. This assumption is plausible when the two groups exhibit parallel trends before treatment. We show this visually in Figure 3a, which plots mean credit card expenditure around modification date. ${ }^{22}$ The same figure shows that principal reduction appears to have little effect-a result we explore in a regression framework.

Formally, our main specification is the following:

$$
y_{i, g, t, s}=\gamma_{g}+\gamma_{t}+\gamma_{m(i), s}+\beta\left(\text { Principal Reduction }_{g} \times \text { Post }_{t}\right)+x_{i t}^{\prime} \delta+\varepsilon_{i, g, t, s},
$$

\footnotetext{
${ }^{20}$ Our main sample for this analysis includes underwater borrowers in the matched HAMP credit bureau dataset who are observed one year before and after modification and report positive credit card expenditure in at least one month during this window.

${ }^{21}$ The contractual frictions are particularly acute with securitized loans. For example, Kruger (2018) shows that 22 percent of servicing agreements governing securitized pools explicitly forbid servicers from reducing principal balances as part of modifications. As a result, principal reduction in HAMP was less common among borrowers in securitized pools (Scharlemann and Shore 2016). Conversely, principal reduction is more common for loans held on banks' own balance sheets, where servicer-lender frictions are mitigated (Agarwal et al. 2011).

${ }^{22}$ Online Appendix Figure 9a normalizes expenditure to zero at modification date in order to more clearly show the parallel pre-trends. Online Appendix Figure 9b plots mean auto expenditure around modification date and similarly demonstrates parallel pre-trends.
} 
where $i$ denotes borrowers, $g \in\{$ payment reduction, payment \& principal reduction $\}$ the modification group, $t$ the number of months since modification, $s$ the calendar month, and $m$ the household's Metropolitan Statistical Area (MSA). Our main outcome variables $y_{i, g, t, s}$ are monthly credit card and auto expenditure, which proxy for non-durable and durable spending, respectively. $\gamma_{g}$ captures the modification group fixed effect and $\gamma_{t}$ captures a fixed effect for each month relative to modification. Principal Reduction R $_{g}$ is a dummy variable equal to 1 for the group receiving modifications with principal reduction while Post $_{t}$ is a dummy variable equal to 1 for $t \geq 0$. The main coefficient of interest is $\beta$, which captures the difference-in-differences effect of principal reduction.

One potential concern is that different geographies were experiencing different trends in their house price recoveries, which affected borrower outcomes. To address this concern $\gamma_{m(i), s}$ captures MSA-by-calendar-month fixed effects. $x_{i}$ is a vector of individual characteristics designed to capture any residual heterogeneity between treatment and control groups. ${ }^{23}$ These characteristics $x_{i}$ are interacted with the Post $_{\tau}$ variable to allow for borrower characteristics to explain changes in underlying trends after modification $\left(x_{i t}^{\prime}=\left(\begin{array}{ll}x_{i} & x_{i} \times \text { Post }_{t}\end{array}\right)^{\prime}\right)$.

\subsection{Results: Effect of Principal Reduction on Consumption}

We find that neither credit card nor auto expenditures are affected by principal reduction in the year after modification. Our main results are reported in Panels A and B of Table 2. In both panels, column (1) reports the most sparse specification, while columns (2)(6) add in additional fixed effects and controls. Across all specifications, the treatment effect of principal reduction on both monthly credit card and auto expenditure is small and statistically insignificant. Our preferred estimate using equation 3 is in column (6), which includes MSA by calendar month fixed effects and interacts control variables with a postmodification dummy. In this specification, our point estimate is that principal reduction of $\$ 67,000$ increases borrower monthly credit card expenditure by less than $\$ 2$ and auto spending by less than $\$ 10$.

Robustness - We address two potential weaknesses of the credit bureau data by confirming that the result also holds in the JPMCI bank dataset. The first potential weakness is that credit card expenditure is inferred from other variables reported by servicers, as discussed in Section 2.1. The second is any measurement error introduced by our matching procedure. The JPMCI dataset covers only one servicer, but does not suffer from either of these two potential limitations. It includes credit card data but not auto loan data.

\footnotetext{
${ }^{23}$ This includes the predicted gain to lenders from providing principal reduction, the predicted gain interacted with a dummy variable equal to one when the gain is positive, borrower characteristics (credit score, monthly income, non-housing monthly debt payment), pre-modification loan characteristics (LTV, principal balance, PTI, monthly payment), property value, origination LTV, and monthly payment reduction. By controlling for the predicted gain to lenders of providing principal reduction, the main difference between our regression discontinuity and difference-in-differences strategies is that the regression discontinuity strategy instruments for treatment with the jump in the probability of receiving principal reduction at the cutoff while the difference-in-differences strategy uses all the variation conditional on the running variable.
} 
Online Appendix Figure 10 shows that the same pattern of credit card expenditure around modification date holds in the JPMCI data. Our estimated treatment effects are displayed in online Appendix Table 3. Here again we find the treatment effect of debt forgiveness on credit card expenditure is small and statistically insignificant.

We also explore the effect of principal reduction on consumption using our regression discontinuity strategy. Our outcome variables are the change in mean credit card and auto spending from the 12 months before modification to the 12 months after modification. The reduced form plots are shown in online Appendix Figure 11. These plots confirm the weakness of this strategy for studying consumption impacts since the strategy suffers from lack of precision. ${ }^{24}$

We are unable to analyze the long-run effects of principal reduction on consumption within our sample window. We discuss potential long-run effects in Section 7.2.

Effect of Payment Reduction on Consumption - A natural concern with our zero result is that our consumption series might not detect responses to important financial changes. However, the paths of credit card and auto spending around modification suggest that borrowers do seem to respond to short-term payment reductions. Both credit card and auto spending are declining before modification and recover after modification. The decline pre-modification is likely a result of financial stress experienced by the borrowers. The slope of expenditure changes sharply around modification, suggesting that lower payments help expenditure to recover.

The apparent positive effect of short-term payment reductions on auto spending is consistent with findings in Agarwal et al. (2017a). That paper exploits regional variation in the implementation of HAMP to estimate the effects of HAMP modifications which combine both short-term and long-term payment reductions. They find that the combined modifications are associated with increased auto spending. If the effect of long-term payment reductions in HAMP is zero, as suggested by our estimates, it makes sense to infer that short-term payment reductions are responsible for the consumption impact they estimate. In online Appendix B.2.2 we attempt to directly estimate the impact of short-term payment reductions on consumption using the payment-reduction regression discontinuity identification strategy in Section 5, but we conclude that this strategy is under-powered for studying consumption impacts.

\subsection{Comparison of Estimated MPC From Principal Reduction to Housing Wealth MPCs}

To help interpret the economic significance of our results, we convert our estimate for the impact on credit card and auto consumption into a marginal propensity to consume (MPC) out of housing wealth. First, we scale up credit card spending to a measure of

\footnotetext{
${ }^{24}$ Translating these estimates to a marginal propensity to consume, as in Section 4.3, our confidence interval ranges all the way from -15 cents to 41 cents.
} 
non-auto retail spending to be comparable to Mian et al. (2013). We do this by adjusting for credit card spending on cards where spending is not reported in the credit bureau data and then multiplying by the ratio of non-auto consumer retail spending to consumer credit card spending in 2012. ${ }^{25}$ Second, we combine with our auto spending measure, annualize, and divide by the mean incremental amount of principal reduction in the treatment group.

Using this method, our point estimate is that households increased annual consumption by 0.3 cents per dollar of principal reduction, with the upper bound of the 95 percent confidence interval corresponding to 0.8 cents. A similar procedure using results from the JPMCI bank dataset yields an upper bound of 1.2 cents. If we normalize by the reduction in the NPV of mortgage payments owed under the new mortgage contract rather than the dollar value of principal reduction, we get a point estimate of 0.5 cents and an upper bound of 1.6 cents.

Our estimated MPC out of housing wealth for underwater borrowers is an order of magnitude smaller than the MPC for average homeowners examined in prior studies. A set of comparison points for our estimates of the impact of principal reduction on consumption comes from the literature examining the impact of price-driven housing wealth changes. We present several such estimates in Figure 3b. Campbell and Cocco (2007) and Mian et al. (2013) find annual MPCs for homeowners around nine cents per dollar of housing wealth gain. Aladangady (2017) finds an MPC of five cents and Carroll et al. (2011) find MPCs between two and ten cents. There is also a wide literature estimating the elasticity of consumption to housing wealth, with findings typically between 0.1 and 0.3 (Guren et al. 2018b, Case et al. 2013, Attanasio et al. 2009, Berger et al. 2018). These elasticities translate into MPCs between three and 11 cents per dollar. ${ }^{26}$

While our estimates are already below those measuring the MPC of average households in the prior literature, there is evidence that highly leveraged borrowers are usually even more responsive. Mian et al. (2013) find that that households living in zip codes with average LTV ratios above 90 have MPCs that are twice that of the median household, translating into an MPC of 18 cents. ${ }^{27}$ This result has been used by policy advocates arguing in favor of principal reduction for underwater borrowers. ${ }^{28}$ However, our evidence suggests that

\footnotetext{
${ }^{25}$ Specifically, our adjustment factor is the product of two ratios: (1) the ratio of the number of credit cards in TransUnion to the number of credit cards with spending reported in TransUnion, and (2) the ratio of non-auto consumer retail spending in 2012 to total consumer credit card spending in 2012 . The first term uses our data, retail spend is from Census, and consumer credit card spending is from Federal Reserve Payment Study (Federal Reserve 2014). This gives an adjustment factor of $(1.2)(2.5)=3.1$. An alternative adjustment multiplying by the ratio of average household monthly non-auto retail spend to the average credit card spending we observe in our sample gives the same MPC point estimate.

${ }^{26}$ For authors who do not report an MPC, we translate elasticities into MPCs by multiplying them by the ratio of personal consumption expenditures from the BEA to housing assets from the Flow of Funds from 2007 reported in Berger et al. (2018), which is 0.34.

${ }^{27}$ Similarly, Disney et al. (2010) analyze panel survey data in the U.K. and find that borrowers who begin the period underwater and end the period above water, and are thus near the 100 LTV threshold, have high MPCs of about 13 cents.

${ }^{28}$ See discussion in Goldfarb (2012).
} 
the response of borrowers who are far underwater, with LTVs far above 90, have much lower MPCs out of housing wealth, rendering principal reductions for underwater borrowers ineffective. In Section 7 we argue that the inability of underwater borrowers to monetize housing wealth can explain the discrepancy between our estimates and those in the prior literature, and we explore the policy implications of this result.

\section{Effect of Payment Reduction on Default}

In this section we analyze the effect of liquidity provision on borrower default. In contrast to our results on the ineffectiveness of principal reduction, we find that immediate payment reduction with no change in long-term obligations significantly reduces default.

\subsection{Variation in Payment Reduction Between Government-Subsidized and Private Modifications}

We analyze the effect of immediate payment reduction by comparing borrowers with government-subsidized HAMP modifications to those with alternative private modifications. Although servicers were required to offer all eligible borrowers HAMP modifications, as described in Section 3.1 not all borrowers were eligible.

To mitigate losses on loans ineligible for HAMP, mortgage owners developed their own private modification programs. During the Great Recession, mortgages could be partitioned into two approximately equally-sized groups. Loans which met certain underwriting criteria, including a maximum loan size and a minimum borrower FICO score, were usually owned or securitized by Fannie Mac and Freddie Mac (the GSEs). Loans which did not meet these criteria were usually underwritten and often securitized by other market actors, such as banks. We analyze borrowers receiving both types of private modifications using the JPMCI bank dataset described in Section 2.2. This includes both GSE and non-GSE borrowers whose mortgages are serviced by Chase and hence were eligible either for a private modification designed by the GSEs or a private modification designed by Chase. As we describe below, the GSE modification and the Chase modification are quite similar.

The design of HAMP and the private modifications we study reflect different views about the most effective way to reduce defaults. HAMP was designed with an explicit 31\% payment-to-income (PTI) ratio target, as we mention in Section 3.1. This target evolved from the National Housing Act of 1937, which established a PTI limit in the federal government's public housing program. Adopting this income ratio target in a modification program assumes that borrowers with high PTI ratios must need much larger payment reductions in order to avoid subsequent default than borrowers with lower PTI ratios.

The first important feature of these private modification programs is that, in contrast to the rigid Payment-to-Income (PTI) ratio target in HAMP, they use a payment-reduction target. ${ }^{29}$ Under this alternative view, the amount of payment reduction relative to the status

\footnotetext{
${ }^{29}$ Chase private modifications target a 30 percent payment reduction. GSE private modifications did
} 
quo is at least as important for reducing defaults as ensuring that the new payment is an "affordable" share of income according to the government's metric. For borrowers with PTI near the 31 percent target, private modifications result in immediate payment reductions that are larger than HAMP.

The second important feature of these private modification programs is that they use maturity extension as a low-cost tool for achieving deeper immediate payment reductions without reducing long-term obligations. A range of contract terms can be modified in order to achieve a given amount of immediate payment reduction. As described in Section 3.1, HAMP reduces payments by first providing interest rate reductions, then maturity extensions, and finally principal forbearance as necessary to achieve the 31 percent PTI ratio target. In contrast, the private modifications we study target larger payment reductions by first extending maturity and amortization terms (which we call maturity extension for simplicity). In this way, deeper immediate payment reductions are offset by continued payments in the long-term.

Both of these distinctive features are visible in Figure 4 for Chase private modifications, which is our preferred estimation sample. (The modification design and point estimates for GSE private modifications are very similar, but the regression discontinuity design has a technical issue which we discuss later in this section.) This figure summarizes payments under each program using the same plot structure as Figure 1. Figure 4a shows the annual path of payments relative to the status quo for government and private modifications offered to borrowers with PTI close to 31 percent. Government (HAMP) modifications for this sample have a modest reduction in payments until year 27 , with small increases thereafter. Private modifications lead to deeper payment reductions for the first 22 years and then to higher payments for the remaining 18 years.

Figure $4 \mathrm{~b}$ shows that compared to government modifications, private modifications offer a relative reduction in immediate mortgage payments but leave the NPV of total payments owed approximately unchanged. This analysis uses the same methodology as in Section 3.1. The main force driving the deeper payment reductions is maturity extension, and when the discount rate equals the interest rate (consistent with the empirical evidence of borrower behavior in Busse et al. 2013), this results in no change in the NPV of total payments owed. Because the private modification has deeper payment reductions for 22 years, it may be NPV-positive from the perspective of a more impatient borrower. Even for such borrowers, we attribute the causal impact of the private modification to its liquidity component because in Section 3 we find that future mortgage payments do not affect default rates.

The mix of other modification characteristics also changed at the cutoff, though these

not have a single payment reduction target, but Farrell et al. (2017) show that the GSE program effectively targeted a payment reduction of about 25 percent. While the HAMP program ended in December 2016, both the Chase and GSE modification programs described in this section are ongoing and their rules are subject to change. Our description of the programs reflects guidelines in place during our analysis period. See Cowley (2017) for more detail about the evolution of private modifications across different market participants. 
changes roughly offset. As shown in the figure, borrowers receiving private modifications had less principal reduction. This is because private modifications are ineligible for the subsidized principal reduction in HAMP. ${ }^{30}$ On the other hand, private modifications had more principal forbearance and slightly deeper interest rate reductions, offsetting the effect of reduced principal forgiveness from an NPV perspective.

\subsection{Identification: Discontinuity in Payment Reduction at the 31 percent Payment-to-Income Ratio}

We use variation generated by HAMP's 31 percent PTI eligibility cutoff and the different payment reduction targets used in HAMP and the private modification program. Since HAMP was designed to reduce monthly payments to 31 percent of a borrower's income, borrowers whose PTI ratio was already below 31 percent were ineligible for HAMP. These borrowers were only evaluated for private modifications.

The difference in modification program rules generates substantial variation in the amount of immediate payment reduction received by borrowers on either side of HAMP's 31 percent PTI eligibility cutoff. Below the cutoff, all borrowers receive private modifications with large payment reductions. Above the cutoff about half of borrowers receive HAMP modifications with small payment reductions (since these borrowers are already close to HAMP's 31 percent PTI target) and about half receive private modifications with large payment reductions (since Chase had a minimum 30 percent payment reduction target). Although borrowers above the cutoff who receive HAMP modifications with a 31 percent PTI ratio target would have received larger payment reductions in the private program, HAMP rules prohibited servicers from offering private sector alternatives to any HAMPeligible borrower, under the assumption that private modifications would not be as effective as those subsidized by the government. Thus the only borrowers above the cutoff receiving private modifications are those failing to meet one of the other eligibility criteria described in Section 3.1. The eligibility cutoff therefore serves as an instrument for borrowers moved from HAMP modifications with small payment reductions to private modifications with large payment reductions.

We make three sample restrictions for ease of exposition, though our central result is unchanged when we lift all three restrictions. First, to focus on a subsample eligible for the full maturity extension treatment, we subset to mortgages whose current terms are less than or equal to 30 years. This maintains 87 percent of the sample. Second, to simplify the calculation of expected payments before and after modification in Section 6.2.1, we restrict to fixed rate mortgages. This maintains 48 percent of observations. ${ }^{31}$ Finally, we drop 254

\footnotetext{
${ }^{30}$ As we discuss above, because we found no independent impact of principal reductions on default in Section 3.3, we attribute the causal impact of this treatment on default to the immediate payment reduction portion of the treatment. In Section 5.3 we provide a bound on our estimate of the effect of payment reduction under the alternative assumption that the principal increase actually had an offsetting effect.

${ }^{31}$ Although these sample restrictions drop a substantial share of observations within our sample, they keep the type of mortgages that were most prevalent during this time period. As a result, these restrictions make
} 
observations between 31 percent and 31.1 percent PTI who receive an amount of payment reduction about halfway between that received by borrowers clearly above and clearly below the cutoff.

We provide the same tests as for our prior principal reduction regression discontinuity strategy. Table $1 \mathrm{~b}$ shows that borrowers in our sample are broadly representative of underwater delinquent borrowers during the recent crisis and similar on observables to the principal reduction sample. Online Appendix Figure 12 shows that predicted default rates based on pre-determined covariates trend smoothly through the cutoff. We provide additional detail on covariate balance in online Appendix B.2.1. Finally, online Appendix Figure 13 shows that borrower density is also smooth around the cutoff.

\subsection{Results: Effect of Payment Reduction on Default}

Figure 5a shows that borrowers below the cutoff receive payment reductions that are 18 percentage points more generous than those received by borrowers above the cutoff. The figure also shows that payment reductions are approximately constant below the cutoff, consistent with the payment reduction target discussion above, and that payment reductions are increasing in PTI above the cutoff, consistent with the PTI ratio target discussion above. The difference in financial impacts at the cutoff are similar to those between government and private modifications discussed above: at the cutoff there is a sharp drop in immediate monthly payments with no significant change in the net present value of total payments owed..$^{32}$

We use a fuzzy regression discontinuity strategy. Similar to equation 2, the estimand for the effect of a 1 percent payment reduction is given by

$$
\tau=\frac{\lim _{P T I \downarrow 31 \%} E[Y \mid P T I]-\lim _{P T I \uparrow 31 \%} E[Y \mid P T I]}{\lim _{P T I \downarrow 31 \%} E[\Delta P a y \mid P T I]-\lim _{P T I \uparrow 31 \%} E[\Delta P a y \mid P T I]} .
$$

We follow the same procedures as in Section 3.2 to estimate $\hat{\tau}$ using borrowers in the JPMCI bank dataset. The sample includes borrowers with PTI ratios between 25 and 80 who we observe for at least two years after modification. ${ }^{33}$ For symmetry around the 31 percent PTI cutoff, most figures in the following sections plot data for borrowers with PTI ratios between 25 percent and 37 percent.

We find that immediate payment reduction significantly reduces default rates. Figure 5b shows the reduced form, plotting the default rate on the y-axis. The figure provides visual evidence that payment reduction reduces default in two ways. First, the default rate falls sharply by 6.0 percentage points relative to a control mean of 31.6 percent at the eligibility

the analysis sample more similar on observables to a representative sample of delinquent borrowers (see Table 1b).

${ }^{32}$ Online Appendix Figure 14 reports conditional means with respect to the running variable for the change in the NPV of payments owed, the amount of principal forgiveness, and the change in the interest rate.

${ }^{33}$ Borrower density thins out above PTI ratios of 80 , and borrowers with PTI ratios below 25 are evaluated according to different program rules. 
cutoff. Second, the slope of the estimated default rates in the bottom panel mirrors the slope of the payment reductions in the top panel; default rates are approximately constant on the left-hand side of the cutoff, consistent with a constant amount of payment reduction, and are falling on the right-hand side of the cutoff, consistent with a rising amount of payment reduction. This pattern is even more striking in online Appendix Figure 15, which plots the first stage and reduced form for borrowers with PTI ratios all the way out to 80 percent. Our point estimate of $\hat{\tau}$ from equation 4 is that an extra one percent payment reduction reduces default rates in the two years after modification by 0.34 percentage point, or by 1.1 percent of the mean above the cutoff.

Robustness - Online Appendix Figure 15 shows that when we remove all three of the sample restrictions described above we find an extra one percent payment reduction reduces default rates by 0.26 percentage point. This reduction is 0.95 percent of the default rate above the cutoff, which is similar to our estimate of 1.1 percent in the baseline sample. Online Appendix Figure 16 shows that our estimates are stable for a variety of alternative bandwidths. Our point estimate is similar (rising to 1.3 percent) if we use the upper bound of our confidence interval from Section 3.3 to adjust for any potential effect of the relative increase in mortgage principal at the cutoff. Online Appendix B.2.1 provides additional detail on this calculation.

We also analyze the effects of immediate payment reduction for GSE-backed loans and find a similar reduction in delinquency. For borrowers ineligible for HAMP, the GSEs offered a private modification that was very similar to the Chase private modification in that it featured a payment reduction target and for most borrowers used maturity extensions prior to any interest rate reduction. Borrowers on the left-hand side receive payment reductions that are 22.4 percentage points more generous than borrowers on the right-hand side and have default rates that are 6.1 percentage points lower. ${ }^{34}$ We estimate that a one percent reduction in payments reduces default by 0.27 percentage point. This reduction is 1.0 percent of the default rate above the cutoff, which is similar to our estimate of a reduction of 1.1 percent for non-GSE loans. It is reassuring that we recover essentially the same point estimate when using a completely different sample of borrowers.

However, the research design for the GSE-backed loans does not pass one of the standard $\mathrm{RD}$ identification checks and hence it is not our preferred specification. There are more borrowers on the right-hand side of the cutoff than on the left-hand side, as shown in online Appendix Figure 20. This issue does not arise because of borrower manipulation of PTI, which would induce more mass on the left-hand side where additional payment reduction

\footnotetext{
${ }^{34}$ The sample of GSE modifications covers the same 2011 through 2016 time period as the sample of Chase modifications. Online Appendix Figures 17, 18, 19 and 20 replicate our 31 percent PTI cutoff analysis for the GSE-backed loans sample. Recall that in online Appendix Figure 14 we showed that there was no change in NPV of payments owed at the cutoff for the non-GSE-backed sample because more interest rate reduction was offset by less principal reduction. Fannie Mae and Freddie Mac did not allow principal forgiveness (even for HAMP recipients) and so in the GSE-backed sample the reduction in the NPV of payments owed is smaller on the right-hand side.
} 
is available. Rather, it arises because eligibility for GSE private modifications required a FICO lower than 620 for borrowers less than 60 days delinquent at the time of modification, while HAMP had no such screen. As a result, there is an imbalance where the left-hand side has no less than 60 days delinquent borrowers with FICO above 620 and the right-hand side has borrowers of all FICO scores and pre-modification delinquency statuses. We are unable to correct this problem because we do not observe FICO in the JPMCI data. Nevertheless, we believe the bias from these extra low-delinquency higher FICO borrowers is small and therefore find this research design to still be informative. ${ }^{35}$ Thus, we find that payment reduction as implemented through both the Chase and GSE private alternatives to HAMP has a substantial effect on default for a wide range of types of borrowers.

\section{Implications: Default}

In this section we discuss the positive and normative implications of our results on default. Our finding that default is responsive to immediate payment reductions but not long-term principal reduction provides support for liquidity-driven theories of default. Because liquidity is the main driver of borrower default decisions, we show that maturity extensions as implemented at the HAMP cutoff can provide deeper payment reductions and reduced default rates in a way that leaves borrowers, lenders, and taxpayers better off. This result can be used to draw lessons for the efficient structure of mortgage modifications in a future crisis.

\subsection{Positive: Liquidity Drives Default}

Our empirical results show that immediate liquidity substantially affects borrower default decisions but that reductions in mortgage principal do not. This suggests that, at least for our sample, immediate liquidity is the main driver of borrower default. This contrasts with strategic default explanations based on the degree of negative equity.

Indeed, quantitatively our results suggest that immediate liquidity provision is a key driver of the default reductions found in two types of prior work analyzing the effect of sustained payment reductions. First, Agarwal et al. (2011) and Haughwout et al. (2016) analyze modifications provided to delinquent borrowers before the implementation of the HAMP program. They find that a one percent immediate payment reduction that also reduces long-term debt obligations is associated with a 1.1 percent to 1.3 percent reduction in default rates. ${ }^{36}$ Second, other authors have analyzed the effect of sustained payment

\footnotetext{
${ }^{35}$ Two pieces of evidence suggest the bias is small. First, we plot predicted delinquency as a function of average observable borrower characteristics in online Appendix Figure 19. There is little change in predicted delinquency at the cutoff. Second, the extra borrowers on the right-hand side are more creditworthy. This change in sample composition will lower average default rates on the right-hand side, leading us to understate the effectiveness of payment reduction.

${ }^{36}$ In addition, Agarwal et al. (2017a) show that HAMP modifications with both short and long-term payment reduction led to significant reductions in default rates, though they do not estimate an elasticity with respect to a given quantity of payment reduction.
} 
reductions for non-distressed borrowers. Although differences in borrower characteristics and baseline default rates makes it difficult to directly compare magnitudes between distressed and non-distressed borrowers, this literature has found that a one percent payment reduction is associated with a 0.8 percent to 2.0 percent reduction in default rates. ${ }^{37}$ The similarity between our estimates of the effect of immediate payment reduction and those of the prior literature analyzing the effect of sustained payment reductions suggests that immediate liquidity provision is a main driver of the default reductions documented in previous work.

These empirical results provide support for double-trigger theories of mortgage default, in which households default when they are underwater and face a liquidity shock. Negative equity is a necessary condition for default because households with positive equity can borrow to make payments or sell the house to avoid foreclosure. However it is not generally a sufficient condition for default because there is option value to staying in a mortgage and because default is costly for borrowers.

For example, Campbell and Cocco (2015) develop a calibrated model and find that in a baseline case with cost-less default the relationship between leverage and default is flat until about 135 LTV. Our empirical evidence suggests that default is insensitive to LTVs even at slightly higher LTV ratios, which is consistent with adding a utility cost of default to this type of model (we show this formally in online Appendix D.3). ${ }^{38}$ The result that borrowers without liquidity shocks do not exercise their default option until substantially underwater is consistent with empirical evidence in Bhutta et al. (2017), who show that the median homeowner without a liquidity shock does not default until their LTV is greater than 174, while the result that default jumps once borrowers are moved from positive to negative equity is consistent with the result in Gupta and Hansman (2018), who find that debt increases lead to increased defaults for option ARM borrowers who start with positive equity.

\footnotetext{
${ }^{37}$ See Tracy and Wright (2012), Fuster and Willen (2017), and DiMaggio et al. (2017). These papers analyze the effect of payment reductions caused by downward adjustments of interest rates for borrowers with adjustable rate mortgages. As Fuster and Willen (2017) discuss, to the extent that borrowers are aware of their mortgage terms and follow the movement of underlying index rates, then these estimates may already be capturing only the liquidity effects of lower payments since borrowers would already have been anticipating and responding to the long-term payment reductions. Similarly, Scharlemann and Shore (2017) analyze the effect of sustained payment increases for non-distressed borrowers in a setting where these payment increases are pre-determined five years ahead of time (resulting from a step up in interest rates as part of a previous mortgage modification). The four aforementioned papers capture the effect of payments on default for the average borrower. Other work looking at the effect for borrowers that choose to refinance by Ehrlich and Perry (2015) and Abel and Fuster (2018) has found larger elasticities.

${ }^{38}$ The 90 th percentile LTV in our principal reduction regression discontinuity sample is 163.
} 


\subsection{Normative Implications}

\subsubsection{Can Maturity Extension Reduce Defaults While Leaving Borrowers, Lenders, and Taxpayers Better off?}

Since the amount of liquidity provision appears more important than the way that liquidity is provided, our results imply that maturity-extension-financed payment reduction may generate a Pareto improvement, leaving borrowers, lenders, and taxpayers all better off. To understand why this is true, it is useful to revisit the particular structure of mortgage modifications around the HAMP eligibility discontinuity we study in Section 5. A borrower who moves from the right-hand side of the cutoff ("control") to the left-hand side ("treatment") sees deeper immediate payment reductions that are offset by continued payments in the long-term. Intuitively, maturity extension is equivalent to the lender "lending" the borrower their monthly payment reductions at the mortgage interest rate, with repayments on this "new" loan beginning at the end of the original mortgage term and continuing through the end of the new loan term.

For borrowers, a maturity extension which moves funds from the future to the present might be particularly valuable in periods of acute economic distress. In our setting, all borrowers are better off in the treatment group under relatively mild assumptions about monotonicity and revealed preference. Borrowers can be divided into four potential groups: those who default under both contracts, those who switch from defaulting to paying on schedule, those who switch from paying on schedule to defaulting, and those who pay on schedule under either contract. The first group defaults under both contracts and is therefore no worse off receiving treatment. The second group is better off because they indicate by revealed preference that the modified loan is more attractive than defaulting. If we assume that default is monotonically decreasing with the extent of payment reduction-the canonical assumption from Imbens and Angrist (1994) needed to identify a local average treatment effect-then there is no one in the third group. Finally, the fourth group is better off because their choice set is expanded; they always have the choice to ignore the maturity extension and repay the loan on the original schedule. ${ }^{39}$

For lenders, a maturity extension will increase the NPV of total payments owed when the mortgage's interest rate is higher than the lender's current discount rate. In this time period the interest rates on new mortgages were a few percentage points below the average interest rate on existing mortgages. Hence, when using current interest rates as a measure of the opportunity cost of capital, extending maturities on existing mortgages would increase the NPV of payments owed to the lender. Although most of the incremental payment reduction at the cutoff we study was achieved from maturity extension, part came from interest rate reduction, which reduces the NPV of payments owed. This works against the maturity

\footnotetext{
${ }^{39}$ Borrowers who recently defaulted on their mortgage are likely to want liquidity and so a low-interest loan is likely to be attractive. Relatedly, Argyle et al. (2017) have shown that there is strong consumer demand for extended maturity in the auto loan market.
} 
extension effect.

In our setting, we find that the NPV of the payments owed under the contract is similar in the treatment and control group. To be specific, online Appendix Figure 14 shows that treatment lowers NPV by $\$ 2,860$ relative to the control group when lenders use a 4.11 percent discount rate, which is the average of the 30-year mortgage rate during our sample period. This is a modest loss and with a standard error of $\$ 2,025$ we are unable to statistically reject that there is no change in the NPV to lenders (consistent with the criteria for a Pareto improvement). This estimate-which assumes that all borrowers repay on schedulehas three shortcomings: some borrowers default (and treatment reduces default), some borrowers prepay their mortgage, and lenders may discount cash flows after year 30 at a higher rate than short-term cash flows.

To address these limitations, we build an expected payments NPV model and find that under plausible assumptions lenders are better off assigning a borrower to treatment. We proceed in three steps. First, we incorporate default by using our causal estimate of the effect of treatment on default. ${ }^{40}$ We combine this with prior evidence on the losses incurred by lenders when borrowers default. ${ }^{41}$ Because treatment significantly reduces default rates, this moves the lender to a gain of $\$ 8,301$. Second, the fact that the payments arrive further in the future means that we need to use a higher discount rate, which decreases the NPV. We estimate a term premium of 32 basis points between 30- and 40-year mortgages by extrapolating from observed mortgage rates (see online Appendix Figure 21), which shrinks the gain to the lender to $\$ 5,279$. Finally, we incorporate realistic prepayment behavior for a final estimate of $\$ 5,350$. We provide more detail on this calculation as well as several robustness checks in online Appendix C.

The finding that lenders are better off from maturity extensions depends on two crucial assumptions. First, we assume that prevailing mortgage interest rates accurately reflect a lender's opportunity cost of capital. But if some lenders are liquidity-constrained (as might be implied by the fall in mortgage originations during this time period), then market rates for those borrowers who can get a mortgage might not reflect a lender's true cost of capital. ${ }^{42}$ We calculate that a lender is better off from treatment as long as her discount rate is below 6.02 percent. Second, we assume that implied mortgage spreads accurately capture

\footnotetext{
${ }^{40}$ Using our causal estimate of the effect of treatment implicitly assumes that maturity extension does not raise defaults outside of the time horizon we observe in the data. This assumption could fail because maturity extension slows the repayment of principal and higher LTVs might raise long-term default rates. However, this higher LTV effect should be weighed against the effect of maturity extension on mortgage payments, which are still lower on average 22 years after modification. After 22 years, all borrowers will have regained positive home equity. It is thus likely that foreclosures are permanently lower under this modification type.

${ }^{41}$ Defaults impose losses on lenders both because the house is underwater and because foreclosed homes sell at a discount relative to their market value. We assume that a foreclosure or short sale causes a lender loss equal to 56 percent of the unpaid balance of the loan, equal to the losses experienced by Fannie Mae on foreclosures and short sales in 2011 (Fannie Mae 2018). In the online Appendix C, we show that our conclusion that lenders are not measurably worse off in terms of expected payments is robust to alternative assumptions about the lender's recovery rate on foreclosures.

${ }^{42}$ Online Appendix Figure 22a shows the time series of mortgage originations during this period.
} 
the lender's disutility from extending the mortgage term from 30 to 40 years. Because of uncertainty over this spread, we show that our results are robust to using a variety of term premium assumptions in online Appendix C. However, the term premium we use in our baseline case (32 basis points) is already significantly higher than the actual 30- to 40-year spread for swaps and corporate bonds in our sample period (two and nine basis points, respectively). Furthermore, the flat swap yield curve during this time period implies that a lender concerned about increased portfolio duration risk from extending mortgage maturities could hedge this risk at low incremental cost.

Finally, taxpayers are also better off from more maturity extensions. The government spent substantial resources subsidizing HAMP modifications above the eligibility cutoff with small payment reductions and high default rates, whereas lenders were willing to provide borrowers below the cutoff private modifications requiring no government assistance which had large payment reductions and low default rates. This suggests that using maturity extensions as the first step in modifying mortgages could have saved substantial taxpayer subsidies.

Indeed, our results raise concerns that HAMP's structure led to the crowding out of alternative private modifications that would have led to lower defaults while saving taxpayer money. The 31 percent PTI target in HAMP means that borrowers with pre-modification PTI ratios below 42 percent received payment reductions smaller than the 30 percent payment reductions offered in private modifications. For these borrowers, an alternative private bilateral modification program such as the ones we study would have resulted in more generous immediate payment reduction and, according to our empirical results, lower default rates without requiring any government subsidy. ${ }^{43}$ About 40 percent of all borrowers with HAMP modifications $(625,000$ borrowers) were in this region, and the government spent approximately $\$ 7$ billion subsidizing potentially less effective modifications for these borrowers. Furthermore, the government explicitly prohibited servicers from offering alternative private modifications to any HAMP-eligible borrower under the (incorrect) assumption that the private modifications would not be as effective as those subsidized by the government. Our data on private modifications and the HAMP-first requirement indicate that HAMP crowded out private modifications that could have been more effective for a large fraction of borrowers in the government program. ${ }^{44}$

\footnotetext{
${ }^{43}$ The results are likely to extend to non-GSE and non-Chase borrowers. Averaging over all private modifications, the average payment reduction was around 20\% (Office of the Comptroller of the Currency 2012), which suggests that the private sector was willing to facilitate substantial payment reductions in the absence of HAMP subsidies. On the other hand, Agarwal et al. (2017a) show that there is important variation across servicers in their capacity to execute mortgage modifications.

${ }^{44}$ While our emphasis is on crowd-out on the intensive margin of the quality of modifications, Agarwal et al. (2017a) provide evidence on the extensive margin in terms of the quantity of modifications. They show that each HAMP modification is associated with about 0.84 more "net" modifications, suggesting that the program did not substantially reduce the total number of private modifications that would have been offered in the absence of the program. They argue that by inducing more borrowers to apply for modifications, HAMP increased the private modification rate of HAMP-ineligible borrowers, offsetting the reduced private modification rate of HAMP-eligible borrowers. Our evidence suggests that at least some of
} 
Our findings that payment reductions can be structured so as to reduce default rates while leaving all parties better off contrast sharply with our findings for principal reduction, which was ineffective even while being costly to both lenders and taxpayers. Future private and public modification programs will have a menu of options for restructuring loans. Our findings suggest that among these options, those that maximize immediate payment reduction are likely to be most effective, and that maturity extension is a particular way to achieve large immediate payment reductions at little cost to lenders and taxpayers. We explore the broader implications of these results for modification design in more detail in the next section.

\subsubsection{Efficient Default-Minimizing Modification Design}

Our empirical research designs capture the two extremes in the debate about mortgage modification design. Recall from the introduction that Treasury Secretary Timothy Geithner has explained that the government's "biggest debate was whether to try to reduce overall mortgage loans or just monthly payments." Our first research design captures the pole of offering borrowers housing wealth by forgiving mortgage principal without any immediate change in liquidity. The second captures the pole of offering borrowers liquidity with approximately no change in wealth. In fact, most of the 10 million government-subsidized and private sector modifications completed during the Great Recession affected both liquidity and wealth. In this section, we explain how our results help to answer the question of how to efficiently design mortgage modifications for all borrowers, and we quantify the potential gains of implementing our proposed design relative to the mortgage modifications that were actually pursued.

Our empirical findings that default is responsive to liquidity but not wealth suggest a simple principle for reducing mortgage defaults: the "best" modification steps are those that achieve immediate payment reduction at the lowest possible cost. The costs of payment reductions must be born by either lenders or taxpayers. Minimizing costs per dollar of immediate liquidity provision will maximize the amount of payment reduction (and hence default reduction) that the market will find privately optimal to provide on its own and identify the most efficient use of government subsidies. Hence, we call modifications that follow this minimum-cost structure "efficient default-minimizing modifications."

To uncover the efficient default-minimizing structure of mortgage modifications we evaluate the five modification steps that were used in various combinations in the public and private modification programs we are aware of: maturity extension, temporary five-year interest rate reduction, principal forbearance, permanent interest rate reduction, and principal forgiveness. These policies all reduce mortgage payments for at least five years, but have very different costs. We calculate these costs for an illustrative mortgage with the

the borrowers pushed from private to HAMP modifications would have received larger payment reductions, and had lower short-term default rates, if they had remained in private modifications designed to emphasize payment reduction rather than an income-ratio target. 
characteristics of the average loan at the HAMP eligibility discontinuity. ${ }^{45}$

We rank modification steps by their cost-effectiveness in Figure 6a. We calculate the change in mortgage terms needed to reduce payments by 10 percent and the change in the NPV of payments owed to the lender from this modification step. We find that maturity extension is NPV-positive by nearly $\$ 20,000$ for the lender because the interest rate on the loan is higher than the lender's discount rate (recall that interest rates on new mortgages fell substantially during the crisis, so the spread between the old rate on the mortgage being modified and the available return on new mortgages widened). Temporary interest rate reductions are NPV-negative, costing about $\$ 14,000$, while principal forbearance, permanent rate reduction, and principal forgiveness are even more NPV-negative with costs between $\$ 22,000$ and $\$ 32,000$. Figure 6 a also shows that the same ranking of policies continues to hold when we examine the change in the NPV of expected payments incorporating the yield curve and the impact of modifications on default and prepayment risk. ${ }^{46}$ Across all modification steps we find that the costs to the lender are lower when we incorporate these features and that the ranking from least cost to highest cost is the same. ${ }^{47}$

We use this ranking to propose efficient default-minimizing modifications for a range of payment reduction targets. As we note above, by efficient we mean that we use the lowest-cost policies first. We assume there are limits to how much some mortgage terms can plausibly change. For example, maturity extension cannot possibly reduce payments below the interest payments on the unpaid balance. We restrict the set of possible modifications using the quantitative limits implemented by the HAMP, Chase, and GSE modification programs: we allow for maturity extension up to 40 years, we allow temporary interest rates to be reduced to 2 percent and we allow permanent interest rates to be reduced to the prevailing 30-year mortgage rate. Adopting these limits makes our characterization of the potential gains from more efficiently-designed mortgage modifications conservative.

The efficient default-minimizing modification uses maturity extension, followed by temporary interest rate reduction, followed by principal forbearance, and never principal forgiveness. In Figure 6b, we depict the cost of such a modification. Maturity extension can

\footnotetext{
${ }^{45}$ This loan has a 6.7 percent fixed interest rate, a 23-year remaining term, an unpaid balance of $\$ 248,000$ and a loan-to-value ratio of 131 percent.

${ }^{46}$ We use the same assumptions to calculate expected payments NPV calculation as in Section 6.2.1. We need one new assumption, which is a function that maps payment reduction to default rates for lower levels of payment reduction. We extrapolate from our evidence on default rates and online Appendix Figure 23 shows the function.

${ }^{47}$ One limitation of this ranking is that it assumes that payment reduction over a five-year horizon is the main driver of a policy's effect on a loan's lifetime default rate. Implicitly, we are assuming that payments in the next five years are the relevant variable for the re-default probability of a borrower who is currently in financial distress. This assumption could be wrong in either direction. On one hand, perhaps reducing payments for one year or three years can deliver much of the same reduction in defaults with even less cost. On the other hand, default could rise substantially when payments rise in year six, though empirical evidence in Scharlemann and Shore 2017 shows that this effect is quantitatively small. A payment increase of about 10 percent in year six raises the default rate in the following year from 3.8 percent to 4.6 percent. Unfortunately, our empirical evidence does not speak to this question and we think that understanding the optimal duration of payment reductions is an important area for future research.
} 
reduce payments by up to 16 percent if the loan term is extended from 26 to 40 years, payments can be reduced by an additional 41 percent by reducing the temporary interest rate to 2 percent, and forbearance can reduce payments even further. ${ }^{48}$ The figure also shows the cost of principal forgiveness. Together these two lines show the envelope of the least and most costly ways to achieve various amounts of payment reduction and hence various amounts of default reduction.

The modification policies actually used during the crisis occupy an intermediate position within the envelope of the most efficient and least efficient policies. Recall that HAMP targets a PTI ratio of 31 percent. This means that borrowers receive widely-varying amounts of payment reduction on the basis of their initial PTI ratio. As discussed in Section 3.1, HAMP first reduces the permanent interest rate, then the temporary interest rate, then extends the mortgage term, and finally does principal forbearance. Figure $6 \mathrm{~b}$ shows that by first reducing the permanent rate, HAMP has a marginal cost for small payment reductions that is very close to the cost of principal forgiveness and much larger than the efficient default-minimizing modification, which uses maturity extension first. HAMP Principal Reduction Alternative (PRA), which offered principal reduction as the first step in a mortgage modification (see Section 3.1 for details) has an even higher cost from payment reductions. The figure shows that HAMP PRA follows the upper envelope of the least efficient policy until a payment reduction of 17 percent is reached. After that, the path of the HAMP PRA line parallels the standard HAMP modification.

In sharp contrast to government-designed HAMP modifications, practitioner-designed modifications are much closer to the efficient frontier. Recall from Section 5.1 that the GSEs and Chase offered most borrowers maturity extension, followed by permanent rate reduction, temporary rate reduction (Chase only), and then principal forbearance. ${ }^{49}$ Because the GSEs and Chase had a specific payment reduction target, we depict them in Figure 6b using dots rather than the lines that we used to depict HAMP.

Potential Gains from More Efficient Modification Design - Our results imply that modifications in a future crisis can be redesigned to make borrowers, lenders, and taxpayers better off. To gauge the magnitude of the potential gains, we evaluate our proposed modification structure in comparison to HAMP, where the median borrower received a 38 percent payment reduction. We consider two ways to quantify the potential gains of more efficient modifications.

First, using our "efficient default-minimizing modification" structure we find that the same median payment reduction could have been provided at $\$ 63,000$ lower cost per mod-

\footnotetext{
${ }^{48}$ Our estimates imply than a lender would break-even by offering a payment reduction of 65 percent through a maturity extension to 40 years, a temporary interest rate reduction down to 2 percent, and principal forbearance of 18 percent of the loan balance. Online Appendix Figure 25a shows that when we incorporate the social cost of foreclosure of $\$ 51,000$ from U.S. Department of Housing and Urban Development (2010), the break-even point for lenders and taxpayers is a payment reduction of 70 percent. Online Appendix Figure 25b shows that the same broad patterns hold for payments owed NPV as for expected payments NPV.

${ }^{49}$ Chase also offered principal forgiveness to some borrowers with high LTVs.
} 
ification to lenders and taxpayers. This is equal to 26 percent of the unpaid balance of a typical loan. ${ }^{50}$ Aggregating over all 1.7 million HAMP modifications, this implies a potential unnecessary cost of $\$ 108$ billion. Taxpayers spent around $\$ 27$ billion subsidizing HAMP modifications (Government Accountability Office 2016). Therefore, our results imply that HAMP could have been designed with no taxpayer subsidies and a much lower cost to investors, while maintaining the same amount of payment reduction.

Alternatively, if we allocate all the gains from redesigning modifications to reducing borrower payments, the same amount of lender and taxpayer cost can be used to achieve substantially more default reduction. Again considering the median HAMP borrower, we find that an additional 33 percentage points of payment reduction could have been provided at the same cost, cutting default rates by one-third. Aggregating over all HAMP modifications, this implies that 240,000 defaults could have been avoided at no additional cost to lenders or taxpayers.

Our proposed approach has benefits beyond improving outcomes for borrowers in a government program. For example, the potential default reduction would be even larger if we considered redesigning all the 10 million public and private modifications completed in the Great Recession. Furthermore, when incorporating the $\$ 51,000$ social cost of foreclosures estimated in U.S. Department of Housing and Urban Development (2010), the default reduction just from re-designing HAMP would have generated $\$ 6$ billion in social value. Taken together, these results suggest that the gains in a future modification program could be divided such that borrowers, lenders and taxpayers all benefit relative to what was implemented in the Great Recession

Another advantage of the efficient default-minimizing modification is that it is likely to generate less ex-ante moral hazard. Some borrowers who did not have a liquidity problem may have defaulted on their mortgages in order to become eligible for the generous subsidies. Mayer et al. (2014) document increased defaults after Countrywide announced a generous modification program. The Home Affordable Refinance Program was specifically created to allow underwater borrowers to refinance without needing to become delinquent to get HAMP. Compared to HAMP, a modification with little change in the NPV of payments owed may not be attractive to borrowers who are current on their mortgages, and, even if it is, the resulting modifications will not be costly to lenders or taxpayers.

\subsubsection{Ex-ante Mortgage Design}

Our empirical results about ex-post debt restructuring also help inform the theoretical debate about optimal ex-ante mortgage design. A number of recent papers have analyzed alternative mortgage contracts with built-in features designed to assist households overcome periods of financial distress. Eberly and Krishnamurthy (2014) propose a fixed rate mortgage

\footnotetext{
${ }^{50}$ Although our estimate of the potential value from well-designed modifications is large, it is similar to prior work by Maturana (2017) showing that private modifications raised the NPV of a loan by 16 percent of the unpaid balance.
} 
(FRM) with a one-time option to convert to an adjustable-rate mortgage (ARM), and Guren et al. (2018a) develop an equilibrium model of the housing market to evaluate this contract. They find that the option to convert to an ARM is more effective than alternative contracts because it front-loads the payment reduction to the borrower, and does so at similar cost to the lender. Our results provide empirical evidence that contracts front-loading payment reductions to households in financial distress will be more effective at preventing defaults than an alternative contract with equal cost to the lender that spreads payment reductions throughout the mortgage term.

Similarly, we also provide empirical support for proposals specifically contemplating the option to extend mortgage maturities. Campbell et al. (2018) compare an ARM with a refinance option to an ARM with the option to temporarily allow for interest-only payments with a corresponding increase in its maturity. They find that this maturity extension option outperforms a refinance option because it provides similar liquidity-provision benefits to borrowers at much lower cost to lenders. Our results show that immediate payment reduction can indeed be effective at reducing defaults even if structured with offsetting payments in the future so as to minimize costs to lenders.

\section{Implications: Consumption}

In this section we explore the positive and normative implications of our consumption results. From a positive perspective, we describe a simple model that clarifies that access to liquidity can explain why the tight link between housing wealth and consumption breaks down for underwater borrowers. We find that collateral constraints drive a wedge between an underwater borrower's MPC out of cash and their MPC out of housing wealth. From a normative perspective, this implies that payment reduction policies are at least 10 times more effective than principal reduction at stimulating the consumption of underwater borrowers.

\subsection{Positive: Liquidity Explains Why Principal Reduction is Ineffective}

In Section 4.3 we showed that our estimated MPC out of housing wealth for underwater borrowers is an order of magnitude smaller than the MPC for average borrowers analyzed in prior studies. Furthermore, prior research had shown that highly leveraged (but still above water) borrowers had even higher MPCs, driving arguments in favor of principal reduction as a way to stimulate consumption during a downturn.

We argue that the inability of underwater borrowers to monetize the wealth gains from principal reduction can explain why they are far less sensitive to housing wealth changes than borrowers in other economic conditions. In the changes examined in prior research, housing wealth gains expanded borrowers' credit access. Mian and Sufi (2014a) show that equity withdrawal through increased borrowing can account for the entire effect of housing wealth on spending between 2002 and 2006. But if homeowners face a collateral constraint 
rather than a "natural" borrowing limit allowing them to monetize the present value of their minimum expected lifetime net worth, principal reductions that still leave borrowers underwater will not immediately relax this constraint. ${ }^{51}$ Indeed, Defusco (2017) shows that a significant fraction of the additional borrowing arising from house price gains is due to relaxing collateral constraints. If borrowers cannot immediately monetize the wealth gained by debt forgiveness, it may not be surprising that they do not respond by increasing consumption. ${ }^{52}$

On the other hand, even if borrowing constraints are not relaxed immediately, it is possible that forward-looking agents building up a buffer of assets could respond if they believed principal forgiveness would relax their constraints in the near future. We calculate that since borrowers remained underwater and collateral constraints had tightened, it would take eight years before the average principal reduction recipient in HAMP would expect to be able to increase borrowing as a result of these principal reductions. A dynamic model of household optimization is useful for understanding whether such a lengthy delay can indeed explain why borrowers did not increase consumption. We describe such a model in the remainder of this section.

\subsubsection{Model Setup Summary}

In order to more formally explore whether access to liquidity can explain why the tight link between housing wealth and consumption breaks down for underwater borrowers, we build a partial equilibrium life cycle model of consumption and default. We leave the details of the model to the online appendix and discuss the main findings here.

The model contains one simple addition relative to the standard life-cycle consumption problem in Carroll et al. (2018): households own a home and can only borrow against their home equity subject to a collateral constraint. When households are far underwater, they are far from the point where the collateral constraint will cease to bind. This means that while debt reductions or house price increases raise housing wealth, households are unable to monetize this wealth in the near term. Conversely, when house prices fall and LTVs are pushed beyond the initial collateral constraint, consistent with real-world mortgage contracts we do not assume households are forced to immediately repay excess mortgage debt. This contrasts with the treatment of debt as a one-period bond present in some of the prior theoretical literature where forced deleveraging creates a strong link between debt levels and consumption (e.g., Eggertsson and Krugman 2012, Guerrieri and Lorenzoni 2017).

The full setup is described in online Appendix Section D.1 and the parameterization is

\footnotetext{
${ }^{51}$ Beraja et al. (2017) document a related channel: underwater borrowers are usually not able to refinance their mortgages. See Carroll (1992) and Aiyagari (1994) for discussions of natural borrowing limits.

${ }^{52}$ The possibility that liquidity can explain the lack of response is also consistent with prior research looking at large price declines. Mian et al. (2013) and Kaplan et al. (2016) both document a non-linearity in the consumption response to house price declines, with a large MPC for small declines but a decreasing MPC for large declines. Mian et al. (2013) suggest that the non-linearity they document could be caused by smaller responses once borrowers become underwater. Similarly, our evidence suggests that for borrowers who start substantially underwater, gains in housing wealth do not affect their consumption.
} 
described in section D.2. In section D.4.1 we show that this simple model can quantitively match estimates in the prior literature for the consumption response to housing price changes of both average and highly leveraged (but above water) households. We now consider its lessons for underwater borrowers.

\subsubsection{Consumption Response to Principal Reduction in Model}

A reduction in mortgage debt levels affects today's consumption through two channels. The first is a future cash-on-hand effect. Reducing mortgage debt reduces a borrower's housing payments over time and increases a homeowner's expected home equity gain when they sell the house. These translate into consumption according to the homeowner's MPC out of cash-on-hand gains at future dates. The second channel is a collateral effect. Reducing debt levels frees up home equity that raises the household's borrowing limit over time. This change translates into consumption today according to the homeowner's MPC out of increased collateral in future dates. We show this decomposition formally in online Appendix Section D.4.2.

This clarifies that the key forces determining the consumption response to debt forgiveness are the timeline under which debt reductions translate into higher cash-on-hand (through lower payments or through home sale) and increased borrowing capacity, and the borrower's MPC out of these future cash-on-hand and future collateral gains. Berger et al. (2018) show that the response to housing wealth gains achieved from increased house prices depends on current home values and the marginal propensity to consume out of wealth. Our analysis adds that the MPC out of wealth gains will depend crucially on a borrower's initial home equity position. Underwater borrowers receiving a dollar of housing wealth are only able to monetize this gain by borrowing or selling their home once they are above water, which may be far in the future. In this case, the consumption response today will depend on a household's MPC out of expected cash or collateral gains far in the future.

In our model, households are unresponsive to cash or collateral gains far in the future. To explain why they are unresponsive, it is helpful to divide households into three categories based on their cash-on-hand relative to permanent income. First, households with low cashon-hand consume all their assets each period. These households are only responsive to cash or collateral they can access today. Second, households with moderate levels of cash-on-hand are building up a buffer of assets. For these households, near-term cash or collateral reduces the precautionary value of saving in the current period and increases consumption. However, cash or collateral grants several years in the future have no precautionary value and do not affect spending. Third, high cash-on-hand households consume only the annuity value of cash grants regardless of their timing. We show this visually by plotting the consumption response to future cash and future collateral gains in online Appendix Figure 26.

The lack of response to future cash and collateral gains can explain why HAMP-type principal reduction failed to increase consumption. We explore this in the model by consid- 
ering the consumption response to principal forgiveness for a household matching the typical HAMP borrower. By design, principal reduction in HAMP had no incremental effect on payments relative to alternative modifications until year six, and we find that it would be eight years before principal forgiveness translated into increased borrowing capacity. ${ }^{53}$ Since no groups of borrowers have strong consumption responses to cash and collateral gains so far in the future, we find that this can explain why HAMP did not lead to increased spending in the short term.

This can be seen visually in Figure 7a, which shows the consumption function out of increasing amounts of principal reduction for borrowers starting at an LTV of 150 (the median LTV for HAMP principal reduction recipients). It shows that the consumption function out of home equity gains is S-shaped, convex in a small region below the collateral constraint, and concave above it. Borrowers are insensitive to principal reductions until such reductions bring them close to their constraint. Principal reduction for deeply underwater borrowers does not relax current constraints and has little precautionary value, hence consumption is unaffected. In online Appendix Section D.4.4 we show quantitatively that the MPC out of HAMP-like principal reduction is close to zero under a variety of alternative parameterizations.

Our result contrasts with debt overhang models in which forced deleveraging leads to depressed consumption. For example, in Eggertsson and Krugman (2012) and Guerrieri and Lorenzoni (2017), debt is modeled as a one-period bond. In this setting, when a credit crunch reduces the borrowing limit, borrowers who find themselves beyond the borrowing constraint are forced to immediately cut consumption in order to delever. Applying this assumption to the mortgage setting implies that when housing prices fall such that the LTV ratio becomes greater than 100, borrowers need to immediately repay their outstanding debt until they are above water. Under this hypothetical scenario, borrowers receiving principal reduction would see immediate decreases in the amount of forced repayment. Principal reduction would increase consumption by reducing debt overhang.

But in practice, as in our model, mortgages in particular are long-term loans. Nothing forces borrowers to immediately delever when they are far underwater. Modeling housing debt as a long-term contract removes a mechanical link between debt levels and consumption present in some of the prior literature, and reduces the expected effectiveness of mortgage debt reduction policies. Other recent papers to consider the effect of debt and housing wealth in settings with long-term contracts include Berger et al. (2018), Chen et al. (2013), Kaplan et al. (2017), and Justiniano et al. (2015).

\footnotetext{
${ }^{53}$ This eight years estimate is based on the HAMP mortgage contract, which left borrowers underwater with a median LTV ratio after modification of 114, an assumption that homeowners can only borrow up to $80 \%$ of the value of their home in this time period, and an assumption of $1 \%$ real annual house price growth based on contemporaneous futures contracts. See online Appendix D.4.3 for details supporting the second and third assumption.
} 


\subsubsection{Wedge Between MPC Out of Housing Wealth and MPC Out of Cash}

The inability to monetize housing wealth drives a wedge between an underwater borrower's marginal propensity to consume out of cash and their marginal propensity to consume out of housing wealth. This can be observed visually in Figure 7b. In this figure we take low-cash-on-hand borrowers at various LTV levels and plot the MPC out of $\$ 1$ of cash or $\$ 1$ of housing wealth gained by principal reduction. As in the empirical results in Mian et al. (2013), borrowers near their collateral constraint have a high MPC out of housing wealth gains. However, borrowers far underwater are unresponsive to housing wealth changes even though they are highly responsive to cash transfers. This highlights one way that housing wealth is special. Because it can only be monetized when borrowers have positive home equity above a collateral constraint, borrowers respond less to housing wealth gains than they do to cash.

\subsection{Normative: Designing Policies to Stimulate Consumption}

Our wedge result implies that high leverage is a bad "tag" for targeting policies that increase housing wealth, even though it is a good "tag" for targeting policies trying to provide cash to borrowers with high MPCs. Our empirical and theoretical results show that principal reduction will fail to stimulate consumption for underwater borrowers. However, our model suggests that low-wealth, underwater borrowers would have an MPC out of cash around 30 cents. This high MPC is qualitatively consistent with the sensitivity of spending to payment reduction from our event study graphs in Figure 3a. It is also quantitatively consistent with DiMaggio et al. (2017) who find that underwater borrowers have MPCs out of cash more than twice as high as non-underwater households.

We find that payment reduction is substantially more cost effective than principal reduction at stabilizing consumption. The government spent an average of $\$ 0.30$ to subsidize each dollar of principal forgiveness in HAMP, for a total government cost of $\$ 4.6$ billion. Our model suggests that if the same amount of money had been spent on direct transfers to borrowers, the partial equilibrium spending increase would have been $\$ 1.4$ billion-ten times more than even the upper bound of our estimates for the consumption response to principal forgiveness would suggest. Policies seeking to raise aggregate demand by increasing the housing wealth of leveraged borrowers will be ineffective precisely when policymakers might otherwise want to use them, i.e., in times when many borrowers are underwater and collateral constraints have tightened.

This finding reinforces the conclusions in Section 6.2.2 about efficient modification design. That section focused on the default-reduction gains from maximizing immediate payment reduction for a given amount of lender and taxpayer cost. Our results here imply that the same structure would also maximize immediate demand stimulus.

Although principal reduction as implemented during the crisis is an ineffective way to provide immediate stimulus, it is possible for principal reduction policies to affect consump- 
tion. We consider two cases. First, although we show that principal reduction has no immediate effect on consumption, in the long-term principal reduction translates into lower payments and increased borrowing capacity and hence should eventually affect consumption. Although we cannot analyze this effect empirically within our sample window, our model shows that consumption would likely begin responding about five years after modification for the average borrower. To the extent that principal reductions were pursued for short-run macroeconomic stabilization, long-run consumption responses will have limited benefit.

Second, more generous principal reductions that did push borrowers above their collateral constraint might have led to some immediate consumption response. However, this would have been an inefficient way to raise consumption. Figure 7 shows that all of the consumption increase is coming from the region near the collateral constraint. This means that a policy of targeting deeply underwater borrowers with more generous writedowns will expend substantial resources in a region with no stimulative effect. ${ }^{54}$ This also points to a limitation of one of Fisher's policy recommendations for reversing "debt deflations" (Fisher 1933). He suggests reflating asset prices. Our results suggest that this may be ineffective at increasing demand for those who are underwater unless pursued aggressively enough to bring them into positive equity.

\section{Conclusion}

In this paper, we explore how borrower liquidity and wealth affect default and consumption decisions through the lens of mortgage modifications in the Great Recession. Using quasi-experimental research designs, we show principal reduction that leaves current mortgage payments unchanged-wealth without liquidity-has no detectable effect on default or consumption. In sharp contrast, we find that immediate payment reduction with no change in the net present value of payments owed-liquidity without wealth-significantly reduces default.

Taken together, these results suggest that liquidity is the key driver of borrower consumption and default decisions. Changes in housing debt are irrelevant for the consumption decisions of underwater borrowers because they are unable to access this wealth. From a policy perspective, we show that distressed debt modifications can be redesigned with substantial potential gains. Applied to the main government program for distressed borrowers during the Great Recession, our results imply that 240,000 defaults could have been avoided at no additional cost to investors or taxpayers.

\footnotetext{
${ }^{54}$ One implication of this result is that a principal reduction policy very early in the crisis before credit supply had tightened and before price declines had pushed borrowers into negative equity might have had a positive effect on consumption.
} 


\section{References}

Abel, J. and Fuster, A. (2018). How Do Mortgage Refinances Affect Debt, Default, and Spending? Evidence from HARP. Technical Report 841, Federal Reserve Bank of New York.

Adelino, M., Schoar, A., and Severino, F. (2016). Loan Origination and Defaults in the Mortgage Crisis: The Role of the Middle Class. Review of Financial Studies, 29(7):1635-1670.

Agarwal, S., Amromin, G., Ben-David, I., Chomsisengphet, S., and Evanoff, D. D. (2011). The Role of Securitization in Mortgage Renegotiation. Journal of Financial Economics, 102(3):559-578.

Agarwal, S., Amromin, G., Ben-David, I., Chomsisengphet, S., Piskorski, T., and Seru, A. (2017a). Policy Intervention in Debt Renegotiation: Evidence from the Home Affordable Modification Program. Journal of Political Economy, 125(3):654-712.

Agarwal, S., Amromin, G., Chomsisengphet, S., Landvoigt, T., Piskorski, T., Seru, A., and Yao, V. (2017b). Mortgage Refinancing, Consumer Spending, and Competition: Evidence from the Home Affordable Refinancing Program. Working Paper 21512, National Bureau of Economic Research.

Aiyagari, S. R. (1994). Uninsured Idiosyncratic Risk and Aggregate Saving. The Quarterly Journal of Economics, 109(3):659-84.

Aladangady, A. (2017). Housing Wealth and Consumption: Evidence from Geographically-Linked Microdata. American Economic Review, 107(11):3415-3446.

Argyle, B., Nadauld, T., and Palmer, C. (2017). Monthly Payment Targeting and the Demand for Maturity. Working Paper.

Attanasio, O. P., Blow, L., Hamilton, R., and Leicester, A. (2009). Booms and Busts: Consumption, House Prices and Expectations. Economica, 76(301):20-50.

Beraja, M., Fuster, A., Hurst, E., and Vavra, J. (2017). Regional Heterogeneity and Monetary Policy. Working Paper 23270, National Bureau of Economic Research.

Berger, D., Guerrieri, V., Lorenzoni, G., and Vavra, J. (2018). House Prices and Consumer Spending. The Review of Economic Studies.

Bhutta, N., Dokko, J., and Shan, H. (2017). Consumer Ruthlessness and Mortgage Default during the 2007 to 2009 Housing Bust. The Journal of Finance, 72(6):2433-2466.

Busse, M. R., Knittel, C. R., and Zettelmeyer, F. (2013). Are Consumers Myopic? Evidence from New and Used Car Purchases. American Economic Review, 103(1):220-256.

Campbell, J. Y., Clara, N., and Cocco, J. F. (2018). Structuring Mortgages for Macroeconomic Stability. SSRN Scholarly Paper ID 3135366, Social Science Research Network, Rochester, NY.

Campbell, J. Y. and Cocco, J. F. (2007). How Do House Prices Affect Consumption? Evidence from Micro Data. Journal of Monetary Economics, 54(3):591-621.

Campbell, J. Y. and Cocco, J. F. (2015). A Model of Mortgage Default. Journal of Finance, 70(4):1495-1554.

Carroll, C., Palmer, N., White, M. N., Kazil, J., and Low, D. (2018). econ-ark/HARK: 0.8.0 (Version pre).

Carroll, C. D. (1992). The Buffer-Stock Theory of Saving: Some Macroeconomic Evidence. Brookings Papers on Economic Activity, 1992(2):61-156.

Carroll, C. D., Otsuka, M., and Slacalek, J. (2011). How Large Are Housing and Financial Wealth Effects? A New Approach. Journal of Money, Credit and Banking, 43(1):55-79.

Case, K. E., Quigley, J. M., and Shiller, R. J. (2013). Wealth Effects Revisited: 1975-2012. Working Paper 18667, National Bureau of Economic Research. 
Chen, H., Michaux, M., and Roussanov, N. L. (2013). Houses as ATMs? Mortgage Refinancing and Macroeconomic Uncertainty. SSRN Scholarly Paper ID 2024392, Social Science Research Network, Rochester, NY.

Cowley, S. (2017). Foreclosure Prevention Returns to the Unknown. The New York Times, https://www.nytimes.com/2017/01/25/business/dealbook/foreclosure-prevention-mortgagelending.html, January 25, 2017.

Defusco, A. A. (2017). Homeowner Borrowing and Housing Collateral: New Evidence from Expiring Price Controls. The Journal of Finance, 73(2):523-573.

DiMaggio, M., Kermani, A., Keys, B., Piskorski, T., Ramcharan, R., Seru, A., and Yao, V. (2017). Interest Rate Pass-Through: Mortgage Rates, Household Consumption, and Voluntary Deleveraging. American Economic Review, 107(11):3550-3588.

Disney, R., Gathergood, J., and Henley, A. (2010). House Price Shocks, Negative Equity, And Household Consumption In The United Kingdom 4. Journal of the European Economic Association, 8(6):1179-1207.

Dobbie, W. and Song, J. (2016). Debt Relief or Debt Restructuring? Evidence From an Experiment with Distressed Credit Card Borrowers. Working Paper, Princeton University and Social Security Administration.

Eberly, J. and Krishnamurthy, A. (2014). Efficient Credit Policies in a Housing Debt Crisis. Brookings Papers on Economic Activity, 49(2 (Fall)):73-136.

Eggertsson, G. B. and Krugman, P. (2012). Debt, Deleveraging, and the Liquidity Trap: A Fisher-MinskyKoo Approach. The quarterly journal of economics, 127(3):1469-1518.

Ehrlich, G. and Perry, J. (2015). Do Large-Scale Refinancing Programs Reduce Mortgage Defaults? Evidence From a Regression Discontinuity Design: Working Paper 2015-06. Working Paper 50871, Congressional Budget Office.

Experian and Wyman, O. (2009). Understanding Strategic Default in Mortgages Part 1. White Paper.

Farrell, D., Bhagat, K., Ganong, P., and Noel, P. (2017). Mortgage Modifications after the Great Recession: New Evidence and Implications for Policy. SSRN Scholarly Paper ID 3083560, Social Science Research Network, Rochester, NY.

Federal Reserve, U. S. (2014). The 2013 Federal Reserve Payments Study. The Federal Reserve System.

Feldstein, M. (2009). How to Save an 'Underwater' Mortgage. Wall Street Journal, August 7, 2009.

Fisher, I. (1933). The Debt-Deflation Theory of Great Depressions. Econometrica, pages 337-357.

Fuster, A. and Willen, P. (2017). Payment Size, Negative Equity, and Mortgage Default. American Economic Journal: Economic Policy, 9(4):167-191.

Geanakoplos, J. and Koniak, S. (2009). Matters of Principal. The New York Times, March 4, 2009.

Geithner, T. (2014). Stress Test. Broadway Books.

Gerardi, K., Herkenhoff, K. F., Ohanian, L. E., and Willen, P. S. (2015). Can't Pay or Won't Pay? Unemployment, Negative Equity, and Strategic Default. NBER Working Paper No. 21630.

Goldfarb, Z. (2012). Economists, Obama Administration at Odds Over Role of Mortgage Debt in Recovery. The Washington Post, November 22, 2012.

Greenwald, D., Landvoigt, T., and Van Nieuwerburgh, S. (2018). Financial Fragility with SAM? SSRN Scholarly Paper ID 3069621, Social Science Research Network, Rochester, NY.

Guerrieri, V. and Lorenzoni, G. (2017). Credit Crises, Precautionary Savings, and the Liquidity Trap. The Quarterly Journal of Economics, 132(3):1427-1467. 
Gupta, A. and Hansman, C. (2018). Selection, Leverage and Default in the Mortgage Market. working paper.

Guren, A. M., Krishnamurthy, A., and McQuade, T. J. (2018a). Mortgage Design in an Equilibrium Model of the Housing Market. working paper.

Guren, A. M., McKay, A., Nakamura, E., and Steinsson, J. (2018b). Housing Wealth Effects: The Long View. Working Paper, page 87.

Haughwout, A., Okah, E., and Tracy, J. (2016). Second Chances: Subprime Mortgage Modification and Redefault. Journal of Money, Credit and Banking, 48(4):771-793.

Herkenhoff, K. F. and Ohanian, L. E. (2015). The Impact of Foreclosure Delay on U.S. Employment. Working Paper 21532, National Bureau of Economic Research.

Holden, S., Kelly, A., McManus, D. A., Scharlemann, T. C., Singer, R., and Worth, J. (2012). The HAMP NPV Model: Development and Early Performance. SSRN Scholarly Paper ID 2194279, Social Science Research Network, Rochester, NY.

Imbens, G. and Kalyanaraman, K. (2012). Optimal Bandwidth Choice for the Regression Discontinuity Estimator. Review of Economic Studies, 79(3):933-959.

Imbens, G. W. and Angrist, J. D. (1994). Identification and Estimation of Local Average Treatment Effects. Econometrica, 62(2):467-475.

Justiniano, A., Primiceri, G. E., and Tambalotti, A. (2015). Household Leveraging and Deleveraging. Review of Economic Dynamics, 18(1):3-20.

Kaplan, G., Mitman, K., and Violante, G. L. (2016). Non-Durable Consumption and Housing Net Worth in the Great Recession: Evidence from Easily Accessible Data. SSRN Scholarly Paper ID 2777320, Social Science Research Network, Rochester, NY.

Kaplan, G., Mitman, K., and Violante, G. L. (2017). Consumption and House Prices in the Great Recession. Working Paper.

Kruger, S. (2018). The Effect of Mortgage Securitization on Foreclosure and Modification. Journal of Financial Economics.

Lee, D. S. and Lemieux, T. (2010). Regression Discontinuity Designs in Economics. Journal of Economic Literature, 48(2):281-355.

Mae, F. (2018). Statistical Summary Tables.

Maturana, G. (2017). When Are Modifications of Securitized Loans Beneficial to Investors? The Review of Financial Studies, 30(11):3824-3857.

Mayer, C., Morrison, E., Piskorski, T., and Gupta, A. (2014). Mortgage Modification and Strategic Behavior: Evidence from a Legal Settlement with Countrywide. American Economic Review, 104(9):2830-2857.

Mian, A., Rao, K., and Sufi, A. (2013). Household Balance Sheets, Consumption, and the Economic Slump. The Quarterly Journal of Economics, 128(4):1687-1726.

Mian, A. and Sufi, A. (2014a). House Price Gains and U.S. Household Spending from 2002 to 2006. Working Paper 20152, National Bureau of Economic Research.

Mian, A. and Sufi, A. (2014b). Why Tim Geithner is Wrong on Homeowner Debt Relief. The Washington Post, May 14, 2014.

of Housing and Urban Development, U. D. (2010). Economic Impact Analysis of the FHA Refinance Program for Borrowers in Negative Equity Positions. Technical report, US Department of the Treasury, Washington, DC.

Office, G. A. (2016). Treasury Should Estimate Future Expenditures for the Making Home Affordable Program. 
Office of the Comptroller of the Currency (2012). OCC Mortgage Metrics Report.

Palmer, C. (2015). Why Did So Many Subprime Borrowers Default During the Crisis: Loose Credit or Plummeting Prices? Working Paper, University of California at Berkeley.

Piskorski, T. and Tchistyi, A. (2010). Optimal Mortgage Design. The Review of Financial Studies, 23(8):3098-3140.

Romer, C. (2011). Policy Responses to the Great Recession: The Interaction of Leadership and Economic Ideas. Speech, Ohio State University, December 1, 2011.

Scharlemann, T. and Shore, S. H. (2017). The Effect of Mortgage Payment Size on Default and Prepayment: Evidence from HAMP Resets. working paper.

Scharlemann, T. C. and Shore, S. H. (2016). Does Reducing Negative Equity Prevent Mortgage Default? Evidence from HAMP's Principal Reduction Alternative. Review of Financial Studies, forthcoming.

Tracy, J. and Wright, J. (2012). Payment Changes and Default Risk: The Impact of Refinancing on Expected Credit Losses. Federal Reserve Bank of New York Staff Reports.

Tracy, J. and Wright, J. (2016). Payment Changes and Default Risk: The Impact of Refinancing on Expected Credit Losses. Journal of Urban Economics, (93):60-70.

United States Department of Housing and Urban Development (2010). Economic Impact Analysis of the FHA Refinance Program for Borrowers in Negative Equity Positions. Technical report, US Department of the Treasury, Washington, DC.

United States Department of the Treasury (2014a). Making Home Affordable Program Handbook for Servicers of Non-GSE Mortgages. US Department of the Treasury, Washington, DC.

United States Department of the Treasury (2014b). MHA Data File User Guide. Treasury White Paper, US Department of the Treasury, Washington, DC.

United States Department of the Treasury (2015). Home Affordable Modification Program Base Net Present Value (NPV) Model v7.0 Model Documentation. Treasury Department Report.

Winkler, R. (2010). Report Shows Strategic Defaults Increasing. Reuters, March 26, 2010.

Zingales, L. (2010). The Menace of Strategic Default. City Journal, Spring 2010. 
Figure 1: Financial Impact of Modifications with and without Principal Reduction

(a) Annual Impacts on Payments

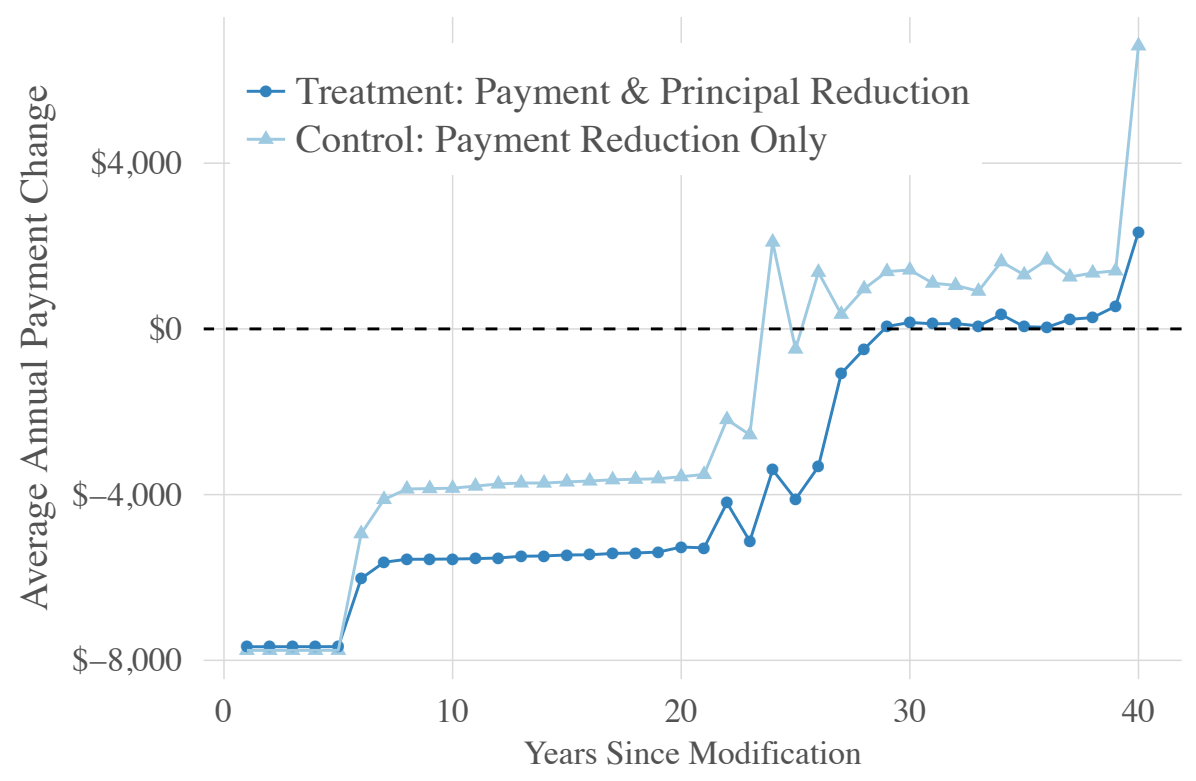

(b) Summary Impact

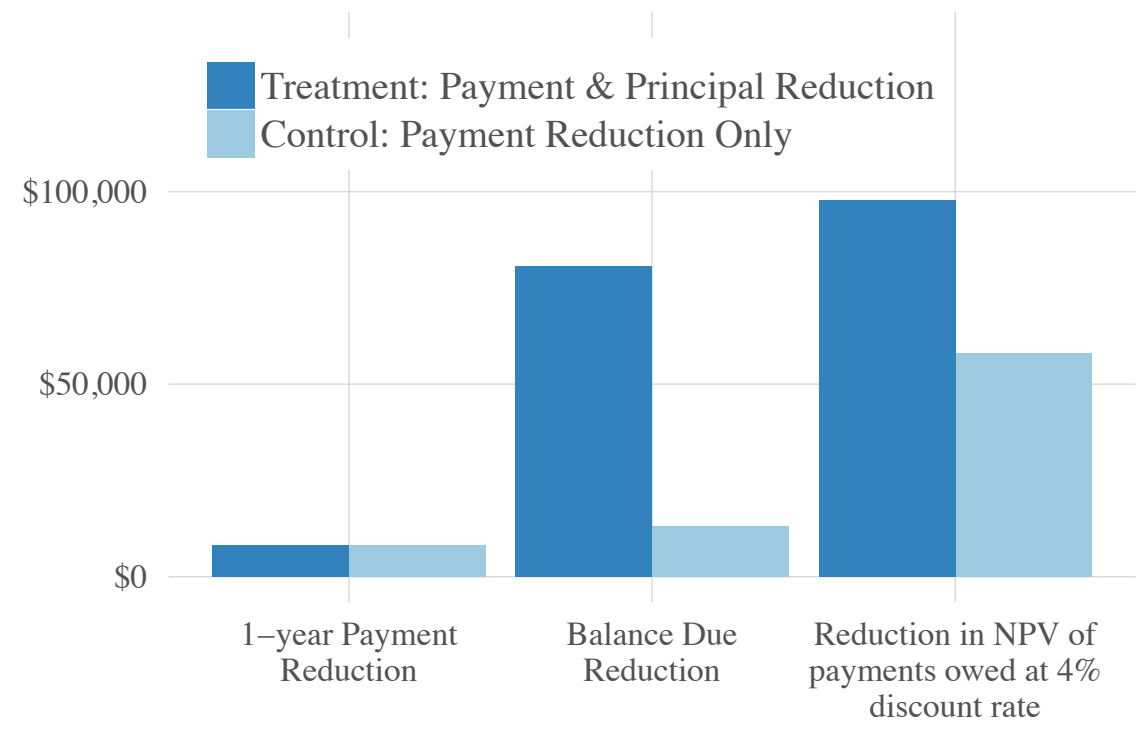

Notes: This figure compares modifications with principal reduction compared to modifications without principal reduction. Panel (a) plots the difference in average annual payments for borrowers receiving each type of modification relative to the payments borrowers owed under their unmodified mortgage contracts in the matched HAMP credit bureau dataset. Panel (b) summarizes the financial impacts of modifications along various dimensions: the change in the one-year payment, the change in the unpaid balance, and the change in the net present value of mortgage payments owed, discounted at a four percent interest rate. See Section 3.1 for details. 
Figure 2: Effect of Principal Reduction on Default

(a) First Stage -- Receive Principal Reduction

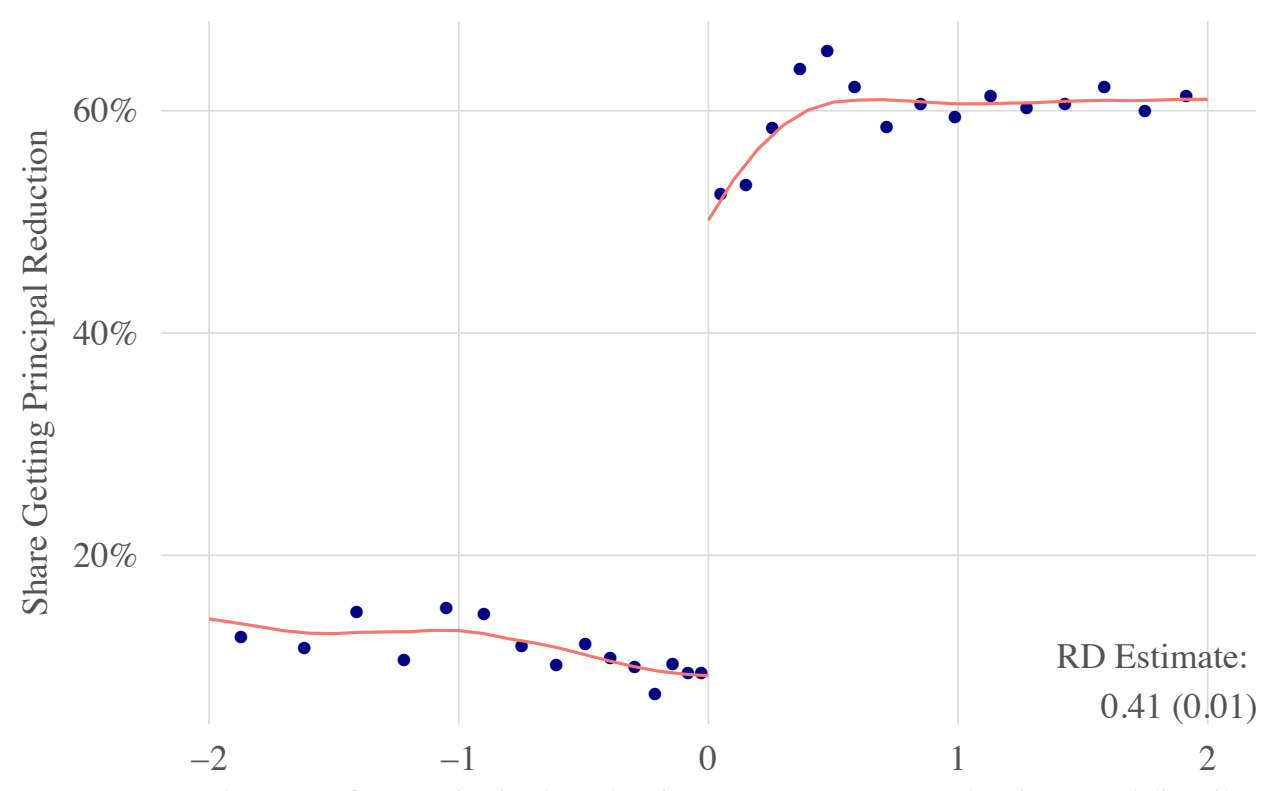

Delta NPV from Principal Reduction over Payment Reduction Mod (in \%)

(b) Reduced Form -- Mortgage Default

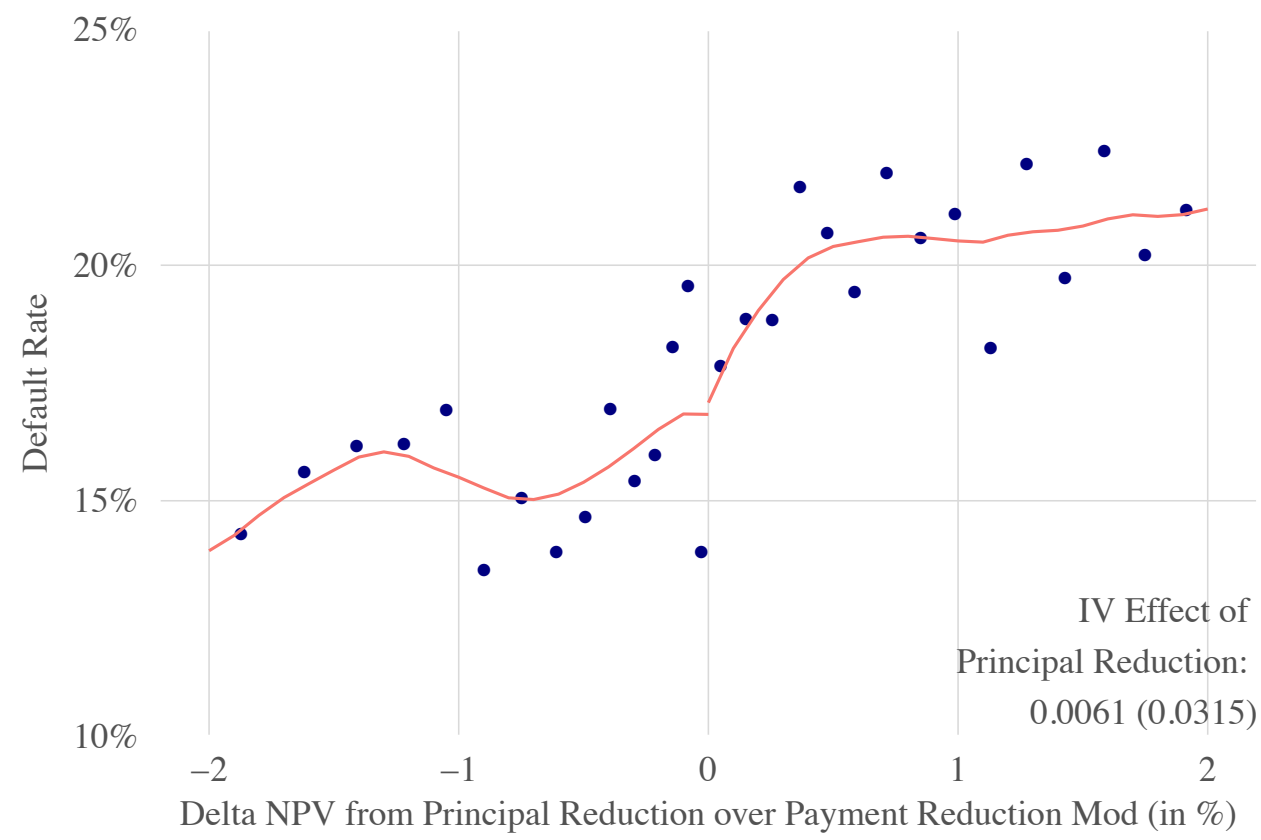

Notes: This figure evaluates the impact of principal forgiveness using a regression discontinuity at the Net Present Value cutoff in the matched HAMP credit bureau dataset. The horizontal axis shows the normalized predicted gain to lenders of providing principal reduction to borrowers from equation 1 . The blue dots are conditional means for 15 bins on each side of the cutoff. The red line shows the predicted value from a local linear regression estimated separately on either side of the cutoff. Panel (a) plots the share of borrowers receiving principal reduction, and panel (b) plots the share defaulting, which is defined as 90 days delinquent between the modification date and March 2015, when our dataset ends. Construction of the IV estimate $\hat{\tau}$ in panel (b) is described in Section 3.2. 


\section{Figure 3: Effect of Principal Reduction on Consumption}

\section{(a) Credit Card Spend Around HAMP Modification}

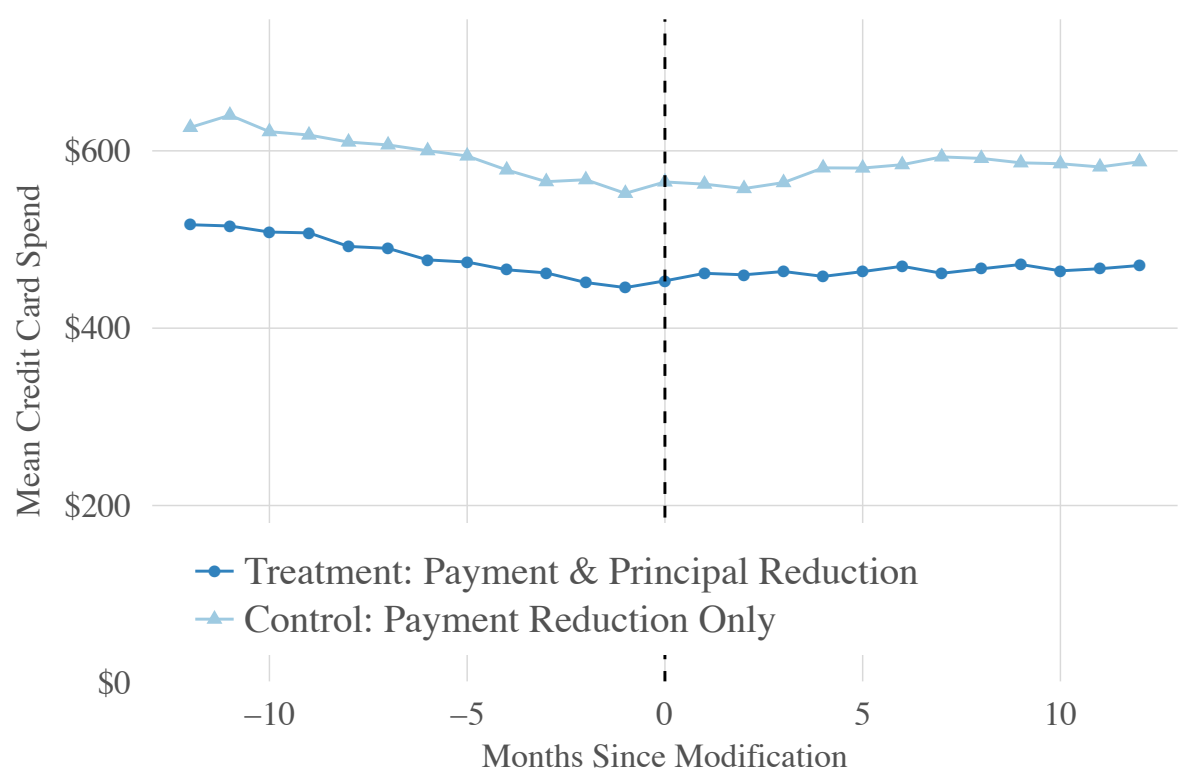

(b) Empirical Estimates of MPC Out of Housing Wealth

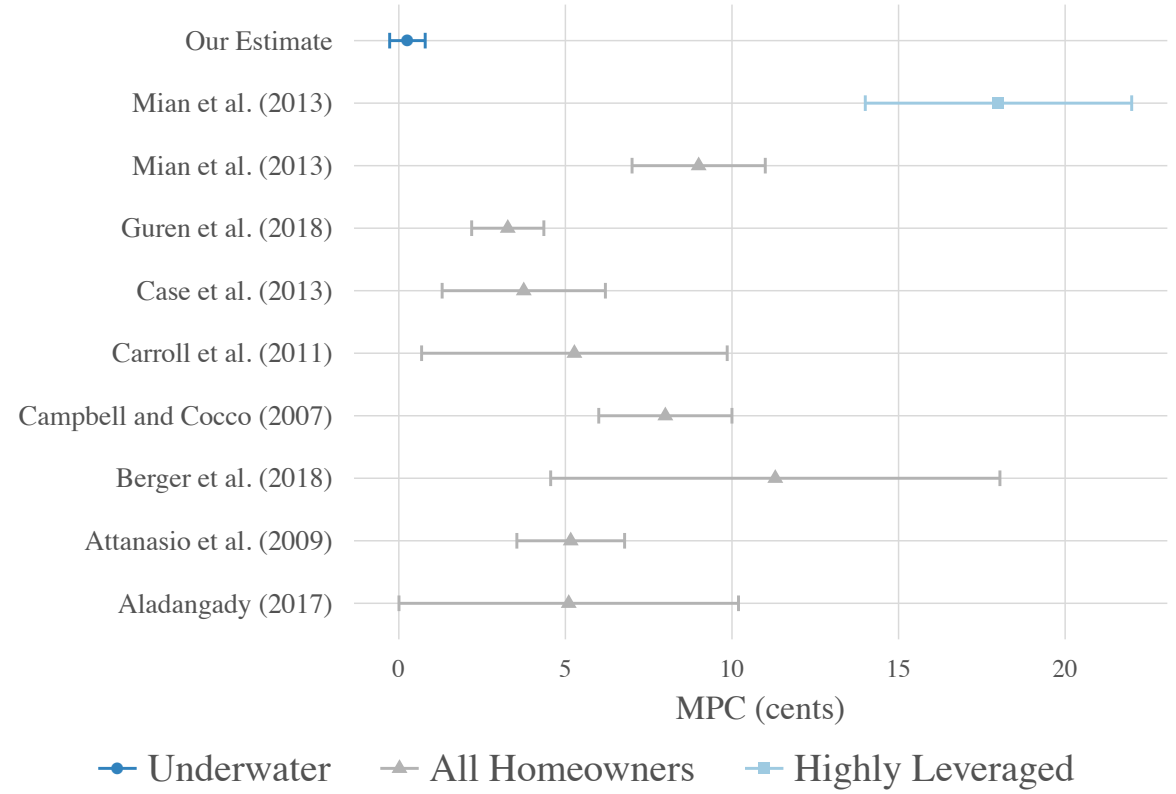

Notes: This figure evaluates the impact of principal forgiveness on consumption. The top panel shows the event study of monthly credit card expenditure around modification for borrowers receiving each type of modification in the matched HAMP credit bureau dataset. The bottom panel plots the point estimate and 95 percent confidence interval for the marginal propensity to consume (MPC) out of housing wealth from various studies. All studies report the MPC for the average borrower unless otherwise indicated. Several studies that report elasticities but not MPCs have been converted into MPCs by scaling the elasticity by the ratio of personal consumption expenditures from the BEA to household housing assets from the Federal Reserve's Flow of Funds from 2007 reported in Berger et al. (2018), which is 0.34. Case et al. (2013) do not report a central estimate, so the range presented is the range of estimates in Tables 3 through 6 , and the point estimate is the mid-point of this range. See Section 4 for details. 
Figure 4: Financial Impacts of Private and Government Modifications

(a) Annual Impacts on Payments

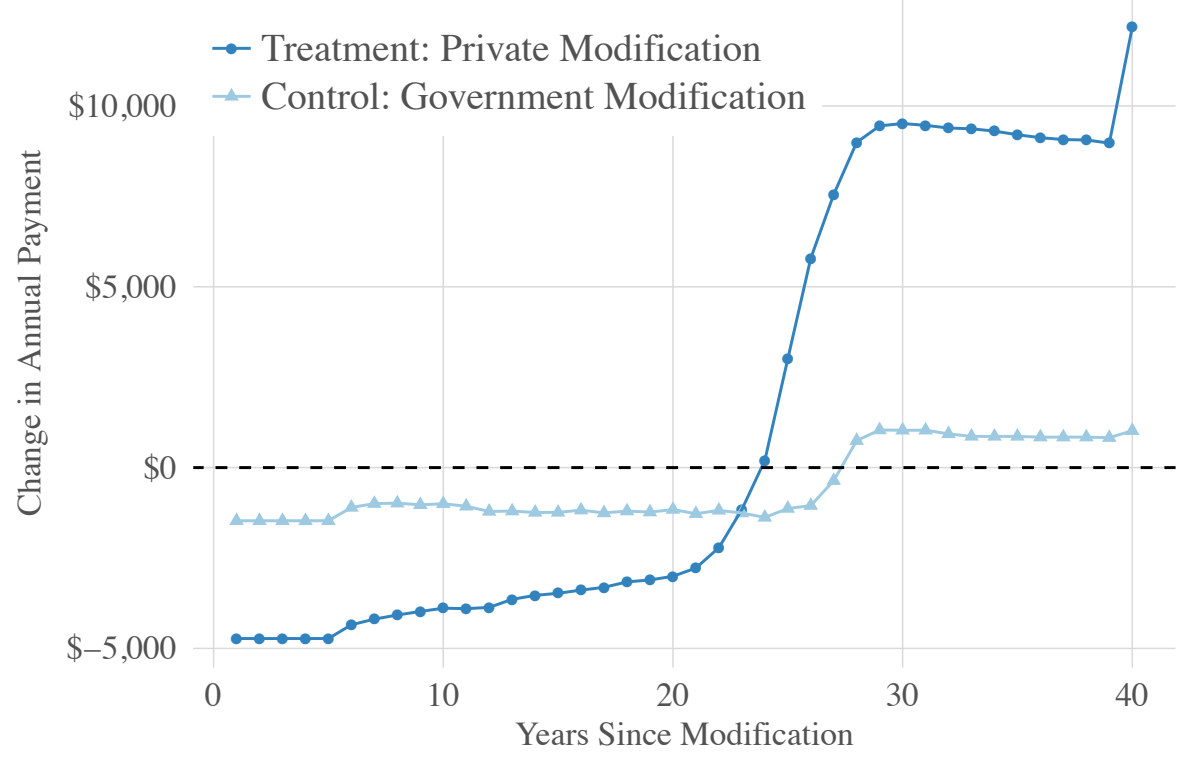

(b) Summary Impacts

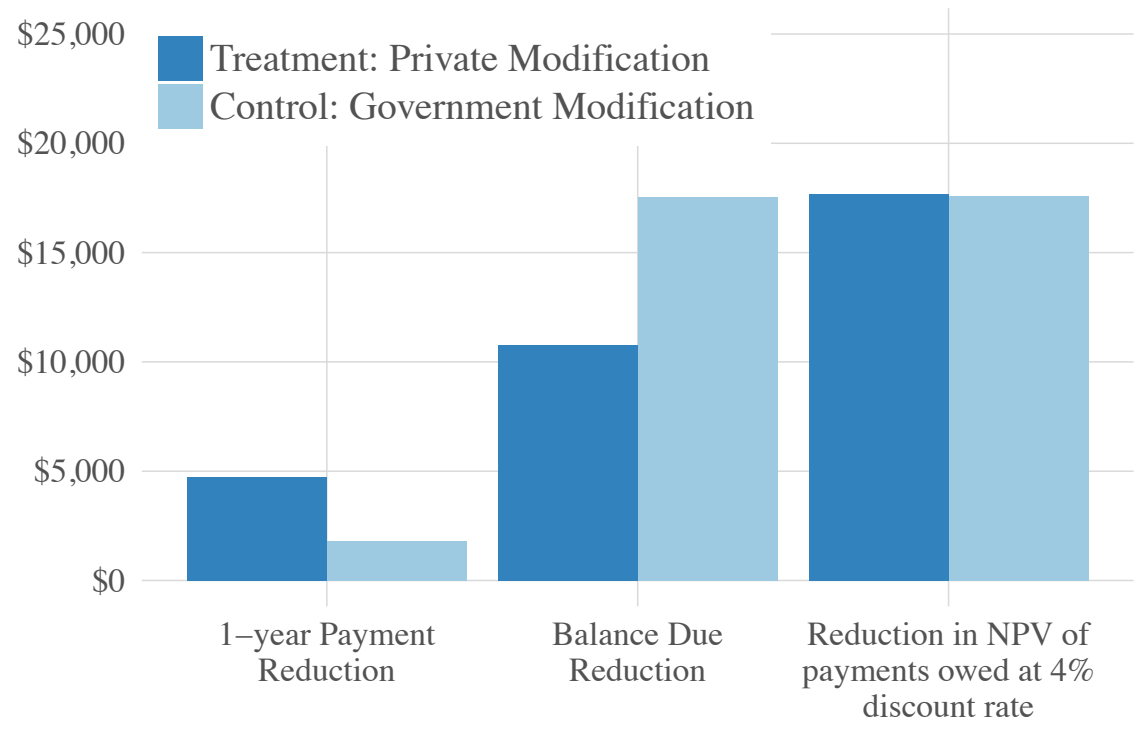

Notes: This figure compares private modifications to government-subsidized HAMP modifications near the HAMP eligibility cutoff. Panel (a) plots the difference in average annual payments for borrowers receiving each type of modification relative to the payments borrowers owed under their unmodified mortgage contracts in the JPMCI bank dataset. Panel (b) summarizes the financial impacts of modifications along various dimensions: the change in the one-year payment, the change in the unpaid balance, and the change in the net present value of mortgage payments owed, discounted at a four percent interest rate. See Section 5 for details. 
Figure 5: Effect of Payment Reduction on Default

(a) First Stage -- Change in Mortgage Payment from Modification

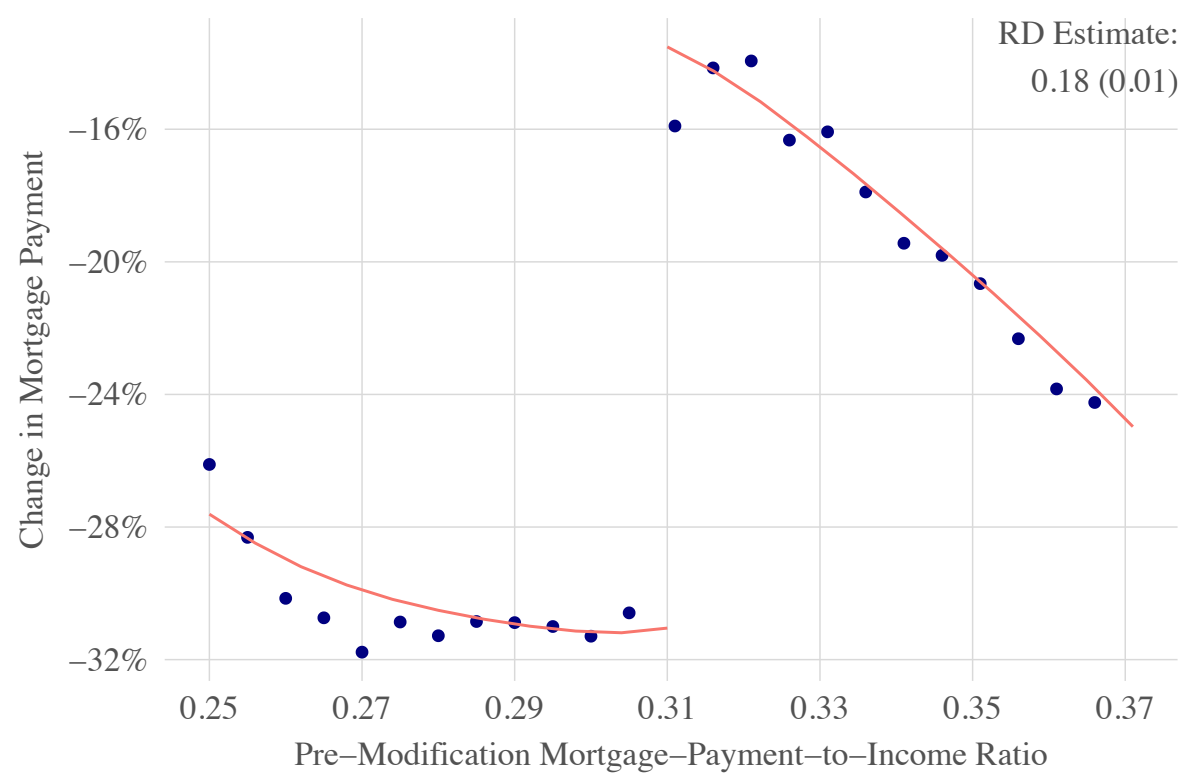

(b) Reduced Form -- Mortgage Default

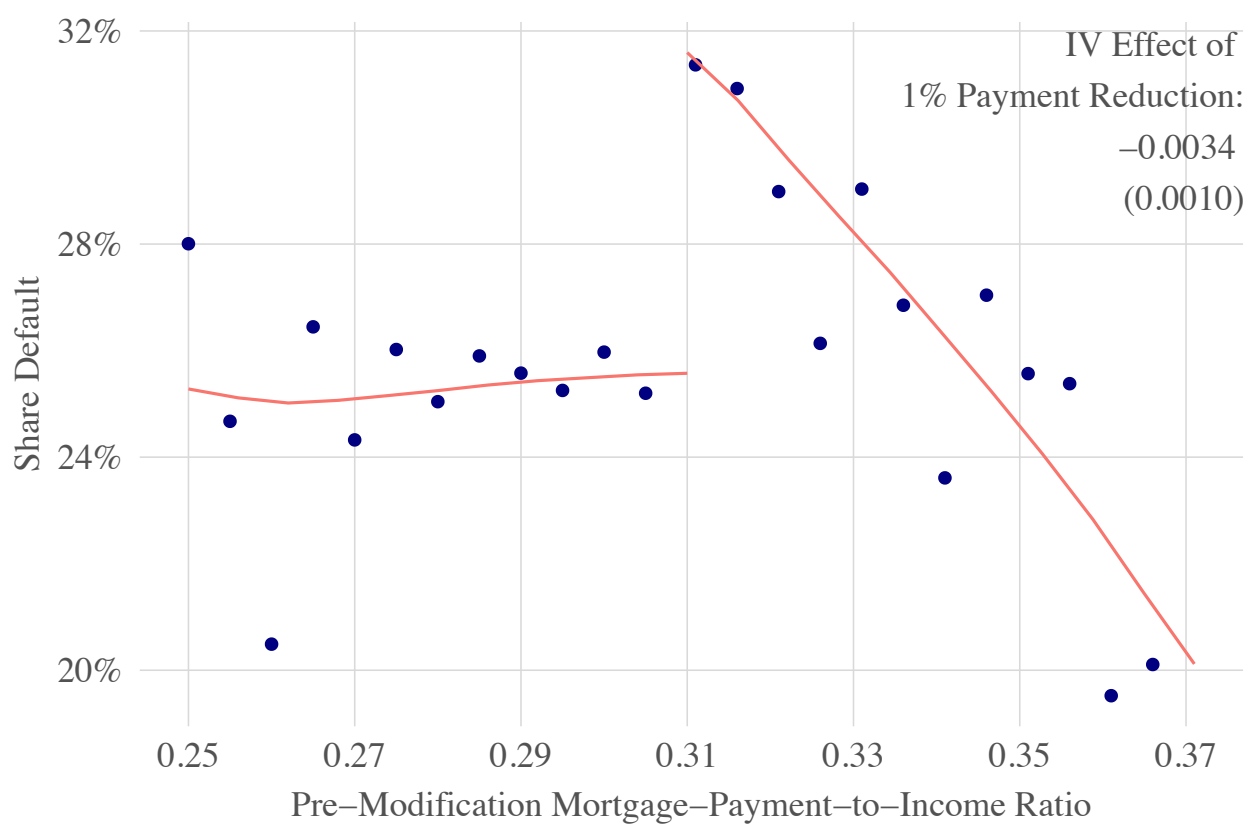

Notes: This figure evaluates the impact of payment reduction on default using a regression discontinuity design around the HAMP eligibility cutoff at the 31 percent Payment-to-Income (PTI) ratio in the JPMCI bank dataset. The horizontal axis shows borrower PTI. The blue dots are conditional means for 12 equally spaced bins on each side of the cutoff. The red line shows the predicted value from a local linear regression estimated separately on either side of the cutoff. On the vertical axis, panel (a) plots mean payment reduction and panel (b) plots the two-year default rate, which is defined as being 90 days delinquent at any point within two years of the modification date. Construction of the IV estimate $\hat{\tau}$ is described in Section 5.2. 
Figure 6: Efficient Default-Minimizing Modifications

(a) Cost to Lender of Reducing Payments by 10\% for Each Modification Step

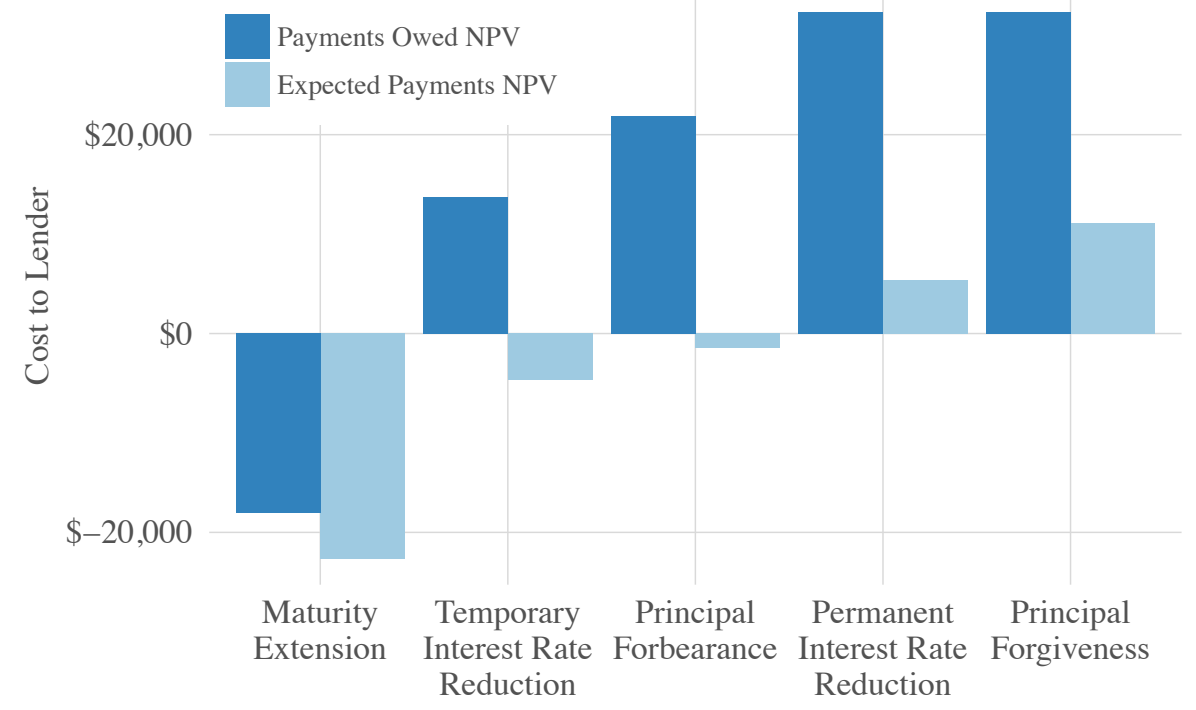

(b) Expected Payments NPV Cost of Payment Reduction for Various Sequences of Modification Steps

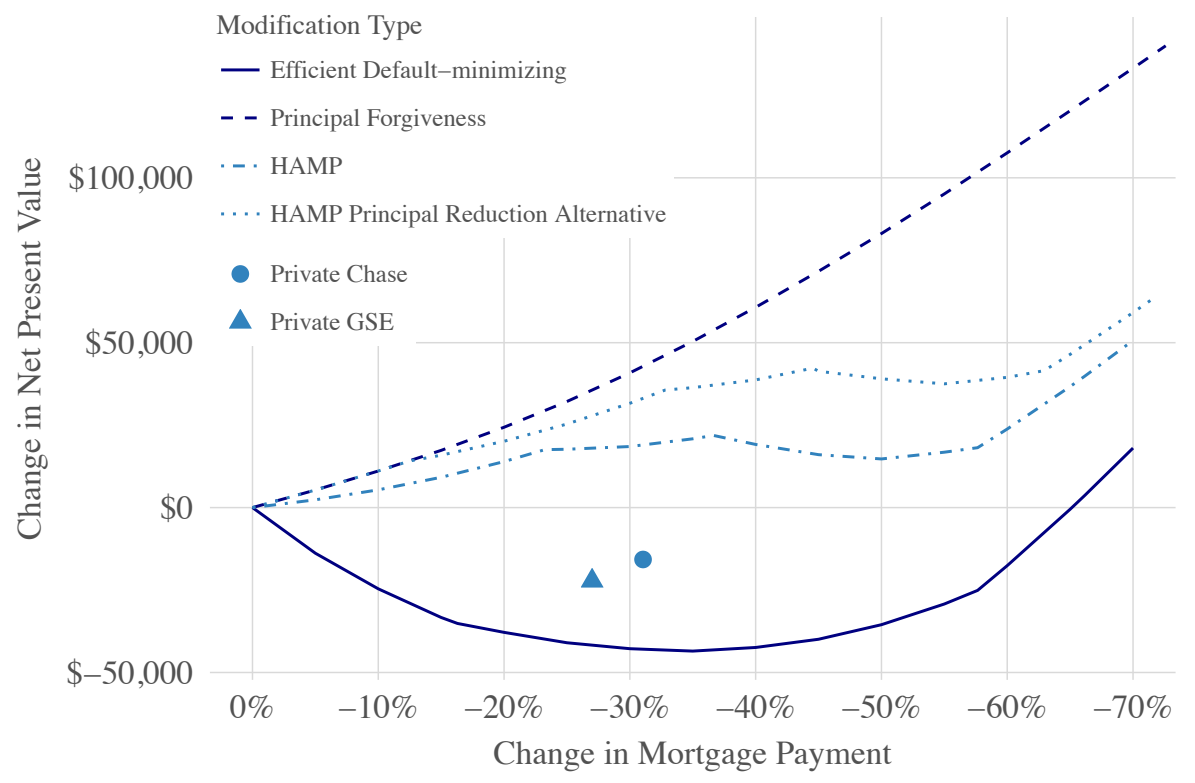

Notes: This figure shows the cost of different mortgage modifications for an illustrative mortgage with the average characteristics of loans at the HAMP eligibility cutoff (a 6.7 percent fixed interest rate, a 23-year term, and a mean unpaid balance of $\$ 248,000$ ). Panel (a) shows the cost of reducing payments by 10 percent for five different possible modification steps. The light blue bars show the change in the NPV of payments owed under the mortgage contract and the dark blue bars show the change in the NPV of expected payments to the lender incorporating the yield curve and the impact of modification on default and prepayment risk. Panel (b) shows the expected payments NPV cost of various modification strategies. The last two programs in the legend are a dot-rather than a line-because they target a specific amount of payment reduction. See Section 6.2.2 for details. 
Figure 7: Consumption and Mortgage Debt Levels in Model

(a) Consumption Function Out of Principal Forgiveness

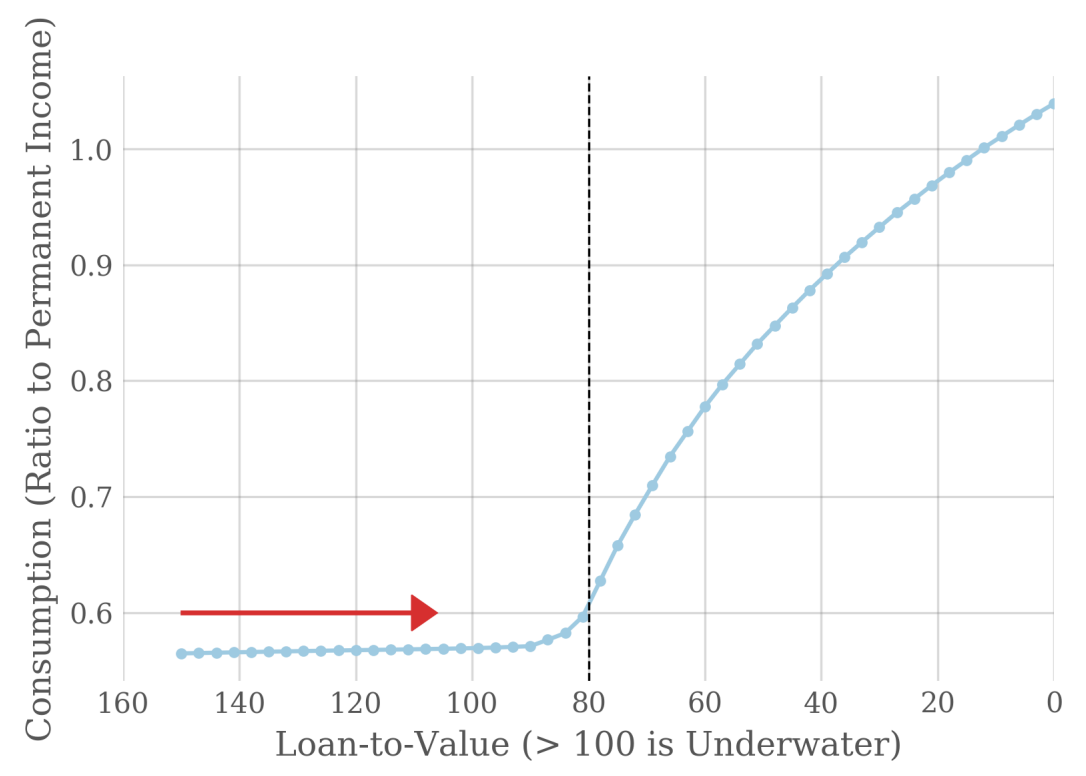

(b) Marginal Propensity to Consume by Home Equity Position

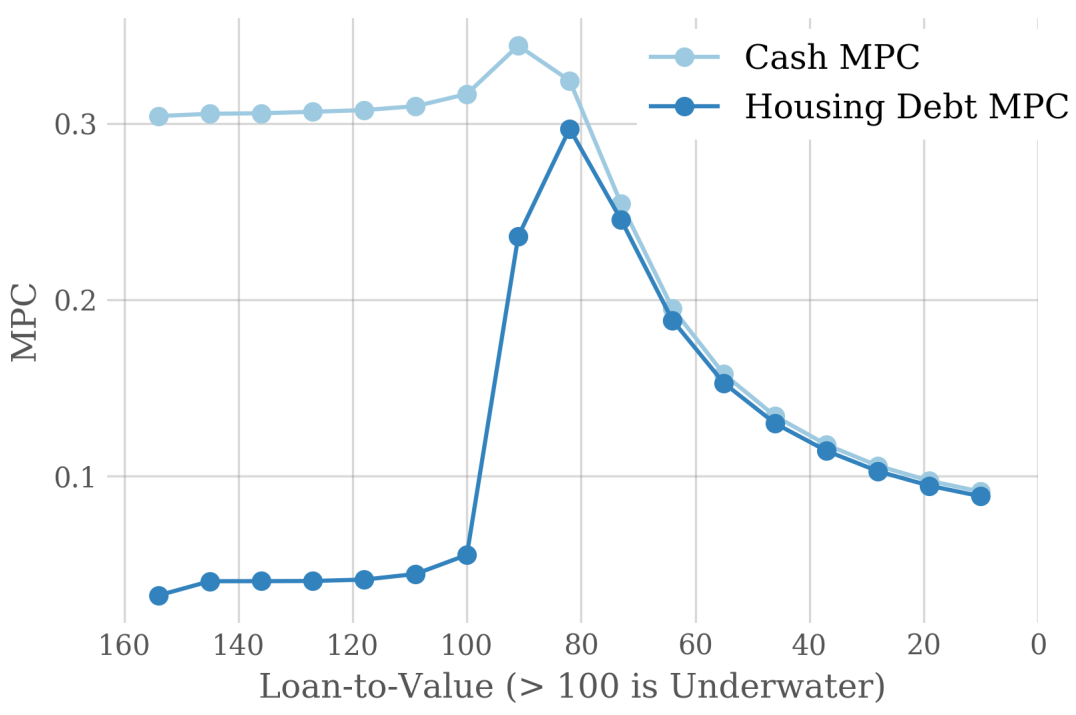

Notes: Panel (a) plots the consumption function out of principal reduction. We begin borrowers at a 150 percent loan-to-value (LTV) ratio and give increasing amounts of principal reduction as necessary to hit a given LTV ratio. To mimic our empirical setting, mortgage payments for households who have not defaulted are fixed for five years, after which payments fall according to the new mortgage balance. The red arrow shows the treatment for the average borrower in the government program. Panel (b) plots the marginal propensity to consume (MPC) out of an additional dollar of cash or an additional dollar of housing wealth generated by mortgage debt forgiveness. In this panel mortgage debt forgiveness is assumed to translate immediately into reduced mortgage payments. Both panels assume a collateral constraint of 80 percent of LTV and cash-on-hand (assets + annual income) of 86 percent of permanent income. See Section 7 for details. 
Table 1: Representativeness

(a) Principal Reduction Regression Discontinuity Sample

\begin{tabular}{lrrrrrrrr}
\hline \hline & \multicolumn{3}{c}{ RD Analysis Sample } & \multicolumn{3}{c}{ PSID Delinquent Households } \\
& Mean & p10 & p50 & p90 & Mean & p10 & p50 & p90 \\
\hline Income & 58,553 & 28,247 & 55,815 & 97,485 & 64,000 & 21000 & 55,000 & 120,000 \\
Home Value & 257,321 & 100,000 & 240,000 & 440,000 & 190,000 & 50000 & 140,000 & 350,000 \\
Loan to Value Ratio & 126 & 100 & 119 & 163 & 101 & 52 & 94 & 166 \\
Monthly Mortgage Payment & 1,803 & 800 & 1,700 & 3,000 & 1,349 & 459 & 1,100 & 2,528 \\
Mortgage Interest Rate & 0.058 & 0.030 & 0.060 & 0.080 & 0.058 & 0.000 & 0.060 & 0.090 \\
Mortgage Term Remaining (Years) & 25.9 & 22.5 & 25.0 & 34.5 & 23.1 & 10.0 & 25.0 & 30.0 \\
Months Past Due & 8.4 & 0.0 & 5.0 & 21.0 & 5.0 & 2.0 & 3.0 & 11.5 \\
Male (d) & 0.60 & 0.00 & 1.00 & 1.00 & 0.68 & 0.00 & 1.00 & 1.00 \\
Age & 48.6 & 36.0 & 46.0 & 66.0 & 43.2 & 31.0 & 42.5 & 57.0 \\
Value of Liquid Assets & & & & & 3,238 & 0 & 250 & 5,000 \\
\hline $\mathrm{N}$ & 9,217 & & & & & & & \\
\hline \hline
\end{tabular}

(b) Payment Reduction Regression Discontinuity Sample

\begin{tabular}{lrrrrrrrr}
\hline \hline & \multicolumn{3}{c}{ RD Analysis Sample } & \multicolumn{3}{c}{ PSID Delinquent Households } \\
& Mean & p10 & p50 & p90 & Mean & p10 & p50 & p90 \\
\hline Income & 67,019 & 26,987 & 54,464 & 123,695 & 64,000 & 21000 & 55,000 & 120,000 \\
Home Value & 188,721 & 49,180 & 139,000 & 390,000 & 190,000 & 50000 & 140,000 & 350,000 \\
Loan to Value Ratio & 131 & 63 & 109 & 211 & 101 & 52 & 94 & 166 \\
Monthly Mortgage Payment & 1,306 & 490 & 1,041 & 2,508 & 1,349 & 459 & 1,100 & 2,528 \\
Mortgage Interest Rate & 0.067 & 0.045 & 0.066 & 0.091 & 0.058 & 0.000 & 0.060 & 0.090 \\
Mortgage Term Remaining (Years) & 22.5 & 15.3 & 24.0 & 26.5 & 23.1 & 10.0 & 25.0 & 30.0 \\
Months Past Due & 9.1 & 1.0 & 7.0 & 24.0 & 5.0 & 2.0 & 3.0 & 11.5 \\
\hline $\mathrm{N}$ & 31,734 & & & 190 & & \\
\hline \hline
\end{tabular}

Notes: This table compares borrowers in our regression discontinuity samples to delinquent borrowers in the 2009 and 2011 Panel Study of Income Dynamics (PSID) Supplements on Housing, Mortgage Distress, and Wealth Data as reported in Gerardi et al. (2015). The principal reduction sample includes borrowers with $|v|<0.5$ of the cutoff (from equation 1) and the payment reduction sample includes borrowers with PTI within 0.057 of the cutoff, the respective optimal bandwidths for each research design. All values are before modification. Panel (b) does not include gender, age, or liquid assets since these are not observed for this sample. The PSID sample includes heads of households who are mortgagors, ages 24-65, are labor force participants, and are 60 or more days late on their mortgage as of the survey date. The summary statistics are repeated in panel (a) and panel (b). Liquid assets include checking and savings account balances, money market funds, certificates of deposit, Treasury securities, and other government saving bonds. (d) indicates a dummy variable. 
Table 2: Impact of Principal Reduction on Expenditure

(a) Credit Card Expenditure $(\$ /$ month $)$

\begin{tabular}{lcccccc}
\hline \hline & $(1)$ & $(2)$ & $(3)$ & $(4)$ & $(5)$ & $(6)$ \\
\hline Treatment (Principal Reduction x Post) & 0.105 & 0.145 & 0.079 & 1.314 & -0.197 & 1.328 \\
& $(3.605)$ & $(3.604)$ & $(3.664)$ & $(3.835)$ & $(3.866)$ & $(3.892)$ \\
\hline MSA Fixed Effects & & Yes & & & & \\
Calendar Month Fixed Effects & & Yes & & & \\
MSA by Calendar Month Fixed Effects & & & Yes & Yes & Yes \\
Controls & & & & Yes & Yes \\
Controls x Post Interactions & & & & & Yes \\
Dependent Variable Mean & 484.01 & 484.01 & 484.01 & 484.01 & 485.74 & 485.74 \\
Observations & $1,692,142$ & $1,692,142$ & $1,692,142$ & $1,692,142$ & $1,655,808$ & $1,655,808$ \\
Adjusted R & & & & & & \\
& 0.003 & 0.018 & 0.005 & 0.015 & 0.081 & 0.081 \\
\hline \hline
\end{tabular}

(b) Auto Expenditure $(\$ /$ month)

\begin{tabular}{lcccccc}
\hline \hline & $(1)$ & $(2)$ & $(3)$ & $(4)$ & $(5)$ & $(6)$ \\
\hline Treatment (Principal Reduction x Post) & 12.382 & 12.387 & 11.881 & 13.372 & 13.965 & 9.216 \\
& $(8.799)$ & $(8.799)$ & $(8.870)$ & $(8.992)$ & $(9.114)$ & $(9.298)$ \\
\hline MSA Fixed Effects & & Yes & & & & \\
Calendar Month Fixed Effects & & Yes & & & \\
MSA by Calendar Month Fixed Effects & & & & Yes & Yes & Yes \\
Controls & & & & Yes & Yes \\
Controls x Post Interactions & & & & & Yes \\
Dependent Variable Mean & & & & & & \\
Observations & 186.48 & 186.48 & 186.48 & 186.48 & 187.29 & 187.29 \\
Adjusted R & & & & & & \\
& $1,692,142$ & $1,692,142$ & $1,692,142$ & $1,692,142$ & $1,655,808$ & $1,655,808$ \\
& 0.001 & 0.001 & 0.001 & 0.003 & 0.004 & 0.004 \\
\hline \hline
\end{tabular}

Notes: This table reports difference-in-differences estimates of the effect of principal reduction on expenditure in the matched HAMP credit bureau dataset. The dependent variable in panel (a) is monthly credit card expenditure, while the dependent variable in panel (b) is monthly auto expenditure computed based on balances of new auto loans. The coefficient of interest, Treatment, is the estimated change in the difference between outcomes of mortgages receiving modifications with and without principal reduction during the year after modification. All specifications include fixed effects for modification type and months since modification. Controls include the predicted gain to lenders of providing principal reduction, the predicted gain interacted with a dummy for this value being positive, FICO score, monthly income, pre-modification loan characteristics (LTV, principal balance, DTI, monthly payment), property value, LTV at origination, non-housing monthly debt payment, and monthly payment reduction. The sample includes underwater borrowers who are observed one year before and after modification and report positive credit card expenditure in at least one month during this window. The dependent variable mean is reported for borrowers receiving principal reduction modifications in the year before modification. Standard errors, in parentheses, are clustered at the borrower level $\left(n_{\text {borrower }}=69,496\right)$. See Section 4 for additional detail on the specification, outcome measures, and sample. 